\title{
"The robustness of the sovereign-bank interconnection: Evidence from contingent claims analysis"
}




\section{$\boxplus|R| E|A|$}

Institut de Recerca en Economia Aplicada Regional i Pública

Research Institute of Applied Economics

Universitat de Barcelona

Av. Diagonal, $690 \bullet 08034$ Barcelona

WEBSITE: www.ub.edu/irea/•CONTACT: irea@ub.edu

The Research Institute of Applied Economics (IREA) in Barcelona was founded in 2005, as a research institute in applied economics. Three consolidated research groups make up the institute: AQR, RISK and GiM, and a large number of members are involved in the Institute. IREA focuses on four priority lines of investigation: (i) the quantitative study of regional and urban economic activity and analysis of regional and local economic policies, (ii) study of public economic activity in markets, particularly in the fields of empirical evaluation of privatization, the regulation and competition in the markets of public services using state of industrial economy, (iii) risk analysis in finance and insurance, and (iv) the development of micro and macro econometrics applied for the analysis of economic activity, particularly for quantitative evaluation of public policies.

IREA Working Papers often represent preliminary work and are circulated to encourage discussion. Citation of such a paper should account for its provisional character. For that reason, IREA Working Papers may not be reproduced or distributed without the written consent of the author. A revised version may be available directly from the author.

Any opinions expressed here are those of the author(s) and not those of IREA. Research published in this series may include views on policy, but the institute itself takes no institutional policy positions. 
We analyze the interconnection between the sovereign and banking sector risk in the peripheral euro area countries over the 2004Q4-2013Q2 period. Applying the contingent claims methodology, we build indicators of sovereign and banking sector risk (incorporating both market and balance sheet based information) and assess their interconnection in comparison with existing market-based indicators of banking and sovereign distress. We use three different statistical measures of interconnection based on principal components analysis, Granger causality network and Diebold-Yilmaz's connectedness index, and apply them to quarterly credit risk data. The empirical results shows strong connectedness and comovement between country-level banking and sovereign risk indicators. We find evidence of bidirectional bank-sovereign linkage for Spain and Italy during the European sovereign debt crisis period. For the late crisis period, we find weak interconnection and more divergence across the various risk indicators. Our findings also suggest that secondary and derivatives market indices are more driven by common underlying factors than are contingent claim based risk measures.

JEL classification: G13, G21, G33, H63

Keywords: sovereign risk, bank risk, sovereign-bank nexus, contingent claims

Marta Gómez-Puig: Risckcenter Research group-IREA. Av. Diagonal 696; 08034 Barcelona ,Spain. E-mail: marta.gomezpuig@ub.edu

Manish K. Singh: Risckcenter Research group-IREA. Av. Diagonal 696; 08034 Barcelona ,Spain. E-mail: manish.singh@ub.edu

Simón Sosvilla-Rivero: Complutense Institute for International Studies, Universidad Complutense de Madrid; 28223 Madrid, Spain. E-mail: sosvilla@ccee.ucm.es

\section{Acknowledgements}

We are very grateful to the seminar participants at the University of Barcelona for helpful comments and suggestions, to Fernando Fernández-Rodríguez for his assistance with the research, to the Comision Nacional del Mercado de Valores for kindly providing the sovereign debt volatility dataset and to Analistas Financieros Internacionales for kindly providing the CDS, yields and credit rating dataset. This paper is based on work supported by the Instituto de Estudios Fiscales [grant IEF 151/2017], the Bank of Spain [grant PR71/15-20229] and the Spanish Ministry of Economy and Competitiveness [grant ECO2016-76203-C2-2-P]. Simon Sosvilla-Rivero thanks the Department of Economics at the University of Barcelona for their hospitality. The opinions expressed in this paper are those of the authors, and they do not reflect in any way those of the institutions to which they are affiliated. Responsibility for any remaining errors rests with the authors. 


\section{Introduction}

The European sovereign debt crisis, which started in late 2009, raised serious concerns about the negative feedback loop between sovereign and bank credit risk. The risk was especially pronounced in peripheral euro area countries, where banks and sovereign CDS spreads started to follow each other very closely. One reason for this increased interconnection was the fear of the development of vicious cycle in which sovereign fragility would jeopardize the asset side of the banks' balance sheet. In turn, bank distress would increase the explicit and implicit bail-out costs for sovereigns, which would endanger public finances and raise questions about their debt sustainability (see Farhi and Tirole (2017), Acharya et al. (2014), Alter and Schüler (2012) among others).

However, there exist some irreconcilable differences between empirical researchers regarding the underlying nature of the sovereign-banking nexus observed. Comparing the sovereign risk of the UK and Spain, De Grauwe (2012) notes the higher default risk premium on government bonds in Spain than in the UK, even though the UK faces less favorable sovereign debt and deficit dynamics and a comparable banking sector risk. De Grauwe argues that this difference in the evaluation of the sovereign default risks is related to the fact that Spain belongs to a monetary union, while the UK does not and therefore has control over the currency in which it issues its debt. This loss of control over the currency makes euro area countries and banks equally dependent on the European Central Bank in times of crisis, thus increasing the linkages between banks and sovereign risk.

Another plausible reason is the 'wake-up call' hypothesis (Goldstein (1998)), according to which a crisis alerts international investors to the need to reassess the creditworthiness of all borrowers. This makes market participants price the same fundamentals differently over time. Comparing the drivers of sovereign risk for 31 advanced and emerging countries, Beirne and Fratzscher (2013) show sharp rises in the sensitivity of financial markets to fundamentals as the main explanation for the rise in sovereign risk between 2008 and 2011, not only for euro area countries but globally. They also note the substantial and sustained differences in the pricing of fundamentals for sovereign risk among euro area peripheral countries before and during the crisis (see also Gómez-Puig et al. (2014)), suggesting the presence of multiple equilibria in this relationship.

In this paper we try to broaden our understanding of the sovereign-bank linkages by statistically assessing the contagion and amplification mechanisms, without taking a clear stand on the causes of the increasing/decreasing interconnection; we are more concerned with the identification of bi-directional linkages between the sovereign and the banking sector and with quantifying the magnitude of that spillover from one part of the system to another and its resulting impact. Our aim is twofold: (1) To quantify the interconnection between banking and sovereign risk; and (2) To document the time-varying nature of these linkages.

We use three different econometric techniques to uncover the underlying interconnection structure in the data and apply them to the quarterly bank and sovereign risk indicators. Our primary credit risk indicator is the contingent claim model-based distance-to-default $(D t D)$ measure for banks and sovereigns. To check the robustness of our results, we use 
two other banking and sovereign risk indicators based on the secondary market (sovereign yield spreads and banking sector equity return) and the derivatives market (banking sector average CDS spreads and sovereign CDS spreads). The econometric techniques we use are: principal component analysis, pairwise Granger causality, and Diebold and Yilmaz's connectedness index. Principal component analysis is used to analyze the interrelationships between the sovereign and the banking sector and to explain these variables in terms of a smaller number of variables with a minimum loss of information. Pairwise Granger causality is applied to identify and quantify the bidirectional bank-sovereign network linkages. Finally, the framework proposed by Diebold and Yilmaz $(2009,2012,2014)$ is used to examine the directional spillovers emanating from each market. Due to data restrictions, our sample spans the period from 2004Q4 to 2013Q2 (i.e., 35 observations) - including four years of the pre-crisis period as well as the peak of the European sovereign debt crisis episode. ${ }^{1}$

While acknowledging the achievements of various studies that identify the sources of systemic risk, we have nonetheless detected a gap in the literature. First, by incorporating the role of multilateral creditors to measure sovereign risk using publicly available data, we try to fill this gap within the framework of the existing theoretical models. Secondly, we quantify the magnitude and direction of interconnection between banking and sovereign risk measures using three alternative risk indicators to provide robust evidence to support or refute previous findings. The idea of interconnection here is not directly related to any grand unifying theory. We assess the interconnection using a variety of statistical measures without imposing any restriction on the dynamics. An exhaustive summary of all plausible reasons for direct and indirect interconnection are presented in Section 3.

Our results suggest that the banking and sovereign credit risk are highly interconnected during the time period we study. Also, there is clear evidence of an increasing role of idiosyncratic risk factors driving the evolution of all the risk indices in the post-crisis period, thus supporting the claims by Beirne and Fratzscher (2013). Country-wise analysis of timevarying bi-directional Granger causal linkages suggest the development of bank-sovereign doom loop only in Spain during the European sovereign debt crisis period. This result is in line with the findings of Singh et al. (2016) where a two-way negative feedback between banks and sovereign risk was also detected using sovereign yield spreads and banking sector average $D t D$ data. The analyses based on Diebold-Yilmaz's connectedness index suggest that increased risk is being driven away from market-based indices to DtD indicators, suggesting that contingent claim based $D t D$ indices capture the balance-sheet based uncertainty and vulnerabilities more precisely.

The rest of the paper is organized as follows. In Section 2 we provide a simple framework for an overview of the idea of interconnection. Section 3 explains the channels via which interconnections arise between sovereign and bank risk with a brief review of the related literature. Section 4 describes the credit risk indicators used in our empirical analysis of the interconnections. Section 5 explains the econometric methodology used to assess the interconnections between the bank and sovereign risk indicators. Section 6 presents the

\footnotetext{
${ }^{1}$ Since our sample ends in 2013Q2, we will not be able to disentangle the effect of the European Central Bank's (ECB's) actions on the sovereign-bank interconnection.
} 
empirical findings, whilst Section 7 offers some concluding remarks.

\section{Interconnection between sovereign and banking institutions: A simple con- ceptual framework}

Let us start with a simple conceptual framework to understand the idea of interconnection. Figure 1 shows the stylized balance sheet of a financial institution and its direct inter-linkages with the sovereign balance sheet. The figure is purely schematic and is not intended to indicate the relative magnitudes of the various parts of the balance sheet. Bank A has three categories of assets - (1) Treasury securities: the banks' total exposure to all treasury securities issued by various sovereigns. Generally, a large part of treasury securities consists of the securities issued by the domestic sovereign (here sovereign A), where the bank is based (home bias); (2) Loans to the real economy: exposures outside the financial network, consisting of claims on non-financial entities, such as mortgages and commercial loans; and (3) Claims on other banks: in-network assets claim on other banks, including the interbank loans and exposures through derivatives.

[Figure 1 about here.]

The bank's liabilities include obligations to depositors, other financial entities and bank's equity holders. Bank deposits in most countries are guaranteed by deposit insurance corporations (either public or private). The interbank obligations arise as a mechanism for banks to manage their liquidity risk and perform maturity transformation. This network serves as a risk-sharing mechanism for banks. However, some of these links become vulnerable in times of crisis and work as channels via which problems are amplified within the network. Bank equity is the owner's capital and is of great interest to regulators. It is kind of skinin-the-game of promoters and shareholders of the bank. The sovereign liabilities consist of Treasury securities issued by the sovereign and explicit/implicit guarantees provided by the government on domestic banks' liabilities.

\subsection{Why does financial interconnection arise? Channels of interconnection}

Consider $N$ financial institutions indexed by $i$ which are distributed across $M$ countries indexed by $j(M<N)$. Consider a financial institution $i$, having a risk exposure $x_{i}$, based in country $j$. Assume that fractions $\alpha_{i j}(j \in 1,2, . ., M)$ of this exposure are directly concerned with the credit worthiness of various countries. Then the home sovereign exposure (home bias) in $i$ 's portfolio will be given by $\alpha_{i j} x_{i}$, while the total sovereign exposure will be $\left(\sum_{j=1}^{M} \alpha_{i j}\right) x_{i}{ }^{2}$ Home exposure is extremely important in assessing the health of the banks' assets. Higher home bias will make banking sector assets extremely sensitive to government health. On the other hand, the high foreign sovereign exposure will diversify the sovereign risk exposure for banks but will provide the incentive for governments to collude if there is a looming threat of bank failure. If the fate of a country's banks is strongly intertwined with

\footnotetext{
${ }^{2}$ The total foreign sovereign exposure will be given by $\left(\sum_{n \in M, n \neq j} \alpha_{i n}\right) x_{i}$.
} 
the health of a neighbouring country, this country will be more supportive of any external interventions to support its neighbour. This may have been the case in the Greek bailout, since there was some exposure to Greece, especially within the German and French banking sectors (Ardagna and Caselli (2014)).

Another factor in the banks' exposure concerns the risk factors idiosyncratic to $i$. These are risk exposure which is direct exposure of banks to their home country's real sector. Let's denote by $\beta_{i}$ the fraction of total bank exposure idiosyncratic to $i$. The idiosyncratic exposure of institution $i$ will then be given by $\beta_{i} x_{i}$. The sum of idiosyncratic exposure of all banks based in country $j, \sum_{i \in j} \beta_{i} x_{i}$ will be the amount of credit available in country $j$. If the amount of available credit contracts, the government might have to step in (we might observe higher unemployment) thus placing a strain on government finances. The government has a choice to bail out either the banks or the real sector directly.

The last factor in the bank exposure is the in-network assets. These are direct 'links' among financial institutions, for instance, interbank loans or derivatives, given by the $N \times N$ matrix $\mathrm{B}$, whose elements $b_{i k}$ denote how much bank $i$ is exposed to bank $k$.

Note that, the sum of the individual component of bank $i$ 's exposure will equal to 1 . Mathematically,

$$
\sum_{j=1}^{M} \alpha_{i j}+\beta_{i}+\sum_{k=1, k \neq i}^{N} b_{i k}=1
$$

Similarly, the total exposure of banks to sovereign $j\left(E_{j}\right)$ will be given by

$$
E_{j}=\sum_{i=1}^{N} \alpha_{i j} x_{i}
$$

Assuming that the returns on the sovereign exposure, idiosyncratic factor and in-network assets for bank $i$ are $\rho_{s}+\epsilon_{s}, \rho_{i}+\epsilon_{i}$ and $\rho_{n}+\epsilon_{n}$ respectively, where $\rho_{s}, \rho_{i}$ and $\rho_{n}$ are constants, while $\epsilon_{s}, \epsilon_{i}$ and $\epsilon_{n}$ are independently distributed random variables with zero mean. We can define the benchmark payoff $\hat{\pi}_{i}$ as what $i$ would receive and we can write it in general as $\hat{\pi}_{i}\left(\rho_{s}, \rho_{i}, \rho_{n}, \epsilon_{s}, \epsilon_{i}, \epsilon_{n}\right)$. For illustration, a simple specification could be:

$$
\hat{\pi}_{i}=\left(\rho_{s}+\epsilon_{s}\right) \sum_{j=1}^{M} \alpha_{i j} x_{i}+\left(\rho_{i}+\epsilon_{i}\right) \beta_{i} x_{i}+\left(\rho_{n}+\epsilon_{n}\right) \sum_{k=1, k \neq i}^{N} b_{i k} x_{i}
$$

However, since the fate of countries $j$ and bank $i$ are intertwined and $i$ also depends on a system of financial institutions via interlinked claims, its actual pay-off differs from $\hat{\pi}_{i}$ in case of crisis. In the following section, we review the literature of models explaining the reasons for this variation. 


\section{Literature: Direct and indirect linkages between sovereigns and banks}

\subsection{Sovereign-bank linkage}

Sovereign and banks have direct linkages via the bank's asset holding channel. Banks hold sovereign debt which makes them vulnerable to the sovereign's deteriorating fiscal fundamentals. Bank distress leading to explicit or implicit government support jeopardizes government finances and its debt sustainability conditions. Indirectly, sovereign debt provides a credit ceiling for domestic banks. Also, the worsening creditworthiness of the sovereign squeezes the fiscal space, leading to deteriorating economic activity that indirectly impacts banks' lending. Hence, in times of crisis, banks and sovereign default risk start moving in locksteps (see Figure 2). Here we will touch upon some of the most recent empirical contributions made in this area by Acharya et al. (2014), De Marco and Macchiavelli (2016), Ongena et al. (2016), Altavilla et al. (2016), Kallestrup et al. (2016) and Horváth et al. (2015).

[Figure 2 about here.]

Using CDS spreads on European sovereigns and banks for the period 2007-11, Acharya et al. (2014) finds empirical evidence to support the bi-directional negative feedback loop between banking and sovereign credit risk during the recent crisis. They also show that bailouts triggered the rise of sovereign credit risk and find evidence for the widening of sovereign spreads, and the narrowing of banking spreads, after a bailout. De Marco and Macchiavelli (2016) and Horváth et al. (2015) show that the bank-sovereign nexus was strongly driven by the moral suasion according to which government-owned banks or banks with politicians on their boards of directors displayed higher home bias and purchased more domestic sovereign debt than did privately-owned banks throughout the 2010-2013 period. They also find the moral suasion to be stronger in countries under stress and where sovereign debt is risky. Using propriety data on banks' monthly securities holdings, Ongena et al. (2016) also show that in times of crisis, European banks in fiscally stressed countries increase their holdings of domestic sovereign bonds in months with relatively high domestic sovereign bond issuance. The effect was also stronger for state-owned banks. Investigating monthly data for 226 European banks from 2007 to 2015, Altavilla et al. (2016) show that the publicly owned, recently bailed out and less strongly capitalized banks reacted to sovereign stress by increasing their domestic sovereign holdings more than other banks, suggesting that their choices were affected both by moral suasion and by yield-seeking. Their exposures significantly amplified the transmission of risk from the sovereign and its impact on lending.

By constructing a simple risk-weighted measure of foreign exposures of banking systems in 17 countries, Kallestrup et al. (2016) show that the foreign asset holdings of the largest banks are an important determinant not only of their own CDS premiums but also of the CDS premium of the sovereign in which the banks reside. Thus, banks' foreign sovereign debt holdings not only impact the banks' own credit risk but also transfer the risk partially to their own sovereigns. The exact opposite is also observed. Studying the relation between bank stock returns from EU countries and the returns on sovereign CDS of peripheral countries 
for 2010 to 2012, Beltratti and Stulz (2015) found the relationship to be negative. Using days with tail sovereign CDS returns of peripheral countries to identify the effects of shocks to the cost of borrowing of these countries on EU banks from other countries, they found that the CDS tail return has a greater effect on banks with greater exposure to the country experiencing that return, but it also has an impact on banks that were not exposed. More pervasive shocks to peripheral countries have a stronger impact on the returns of banks from countries that experience no shock more than do shocks to small individual peripheral countries.

\subsection{Bank-bank linkage}

Direct bank linkages arise from the network of bi-directional claims that banks hold against each other (as shown in Figure 1). These network connections usually have positive effects as they diversify the risk exposure of individual banks. However, they also open channels through which negative shocks can spread throughout the system. The rest of this subsection explains the channels via which negative shocks propagate in our current financial system.

i. Direct loss SPillovers through Default: Imagine an entity that has sold guarantees in the form of Credit Default Swaps and reneges on its contractual obligation at the payment date. In this case, the default of this entity can bring down all its counterparties, causing cascading losses and collapses throughout the financial system (e.g., the case of AIG in the summer of 2008). Eisenberg and Noe (2001) provided the basic network model that became the backdrop for much subsequent work on contagion in financial networks.

ii. MARK-TO-MARKET LOSS: Losses in the financial network can spread from one node to another through changes in the market value of underlying assets. When market prices drop, financial intermediaries need to liquidate their assets in order to meet funding and collateral constraints. These new sales amplify the downturn, leading to further sales, and so on, leading to a self-reinforcing liquidity crisis. Allen and Gale (2004), Brunnermeier and Pedersen (2009) and Diamond and Rajan (2005) present different mechanisms via which this can affect market conditions.

iii. FUnDING RUN: When short-term funding becomes scarce, the financial institutions which have high dependence on short-term funding find it extremely difficult to rapidly adjust to the new situation. This creates fear among market participants who start to hoard excess liquidity as a precautionary measure, leading to further liquidity shortage - as happened during the days following the Lehman bankruptcy. Heider et al. (2015) provide evidence of interbank market freeze during the 2008 financial crisis while Acharya et al. (2011) does so for the case of repo markets.

iv. InFORMATION CONTAGION: A disclosure by one bank regarding its assets may lead creditors to make inferences about the assets held by other banks, producing "information contagion." If one bank is forced to sell illiquid assets and in so doing drives down the price of these assets, then other banks holding similar assets incur fire-sale externalities through the price drop (see Chen (1999), Acharya and Yorulmazer (2008b), Aghion et al. (2000) and Acharya and Thakor (2016)). 
v. Contagion through Correlation: Shock outside a particular asset class can force banks to sell their most liquid securities in order to raise cash quickly. This transfers the negative shock from a less liquid asset class to highly liquid market securities. Other market participants observing this sale can join in the sell-off, and this pattern can continue for a few days. Khandani and Lo (2011) document this rapid deleveraging for quant hedge funds in August 2008. Note that these are not conventional fire sale, as the assets sold are highly liquid.

vi. Common exposure: Banks expose themselves to the same risk by investing in similar assets. This may be due to the negative externalities arising from the failure of another bank (see Acharya and Yorulmazer (2008b); Acharya (2009)) or the herding behaviour generated by the financial regulations as shown in Farhi and Tirole (2012) and Acharya and Yorulmazer (2008a).

\subsection{Sovereign-sovereign linkage}

Sovereigns are not directly linked to each other. However, in times of crisis, they do coordinate and support each other by providing foreign currency credit lines to central banks in order to mitigate tensions arising in the foreign currency markets. Sovereigns implicitly guarantee these foreign currency loans. An indirect way in which sovereigns might be connected is the 'wake-up call' hypothesis suggested by Goldstein (1998). Since financial markets become more sensitive to market fundamentals in times of crisis, the system moves to a new equilibrium where the same risk is priced differently (see Beirne and Fratzscher $(2013))$.

\section{Bank and sovereign risk indicators: Data and preliminary analysis}

To measure the vulnerability of banks and sovereigns, we use the contingent claims literature and derive a set of credit risk indicators. To validate our results, we compare them with other market-based indicators of bank and sovereign risks. The variables and data sources are summarized in Table 1.

\section{[Table 1 about here.]}

\subsection{Banking sector risk measures}

To assess the banking sector risk in each individual country, we use three different bank risk measures. Two of them are standard market-based measures, while the third one is based on both market and balance sheet based information. The rest of the subsection enumerates them in greater detail.

\subsubsection{Banking sector average DtD (BankDtD)}

Based on the contingent claim literature pioneered by Black and Scholes (1973) and Merton (1974), we use $D t D$ as the bank risk indicator. Its foundation lies in the isomorphic relationship between equity and call options. Since equity is a junior claim to debt, it can 
be modelled as a European call option on the firms' assets $(A)$ with an exercise price equal to the face value of debt $(D)$.

Calculation method: Consider a bank having simple capital structure with $N$ shares of common stock (market capital $E$ ) and all debt denominated as zero coupon bonds (market value $F$, maturity $T$ ). Using value conservation equation:

$$
A=E+F
$$

Assuming that the assets returns follow Generalized Brownian Motion, the Black-Scholes option pricing formula yields:

$$
E=A N\left(d_{1}\right)-e^{-r T} D N\left(d_{2}\right)
$$

where,

- $N(*)$ is the cumulative normal distribution;

- $r$ is the risk-free rate under risk-neutrality;

- $d_{1}=\frac{\ln \left(\frac{A}{D}\right)+\left(r+0.5 \sigma_{A}^{2}\right) T}{\sigma_{A} \sqrt{T}} ;$ and $d_{2}=d_{1}-\sigma_{A} \sqrt{T}$.

Applying Ito's Lemma, the asset volatility $\left(\sigma_{A}\right)$ can be linked with equity volatility $\left(\sigma_{E}\right)$ as:

$$
\sigma_{E}=N\left(d_{1}\right) \frac{A}{E} \sigma_{A}
$$

Inverting Eqs. 2 and 3 and numerically solving for $A$ and $\sigma_{A}$ yields the $T$ periods ahead $D t D$ as:

$$
D t D=\frac{A-D}{\sigma_{A} A}
$$

Once individual banks' $D t D$ are calculated, following Harada et al. (2010), we consider the banking sector risk as the simple average of individual DtD (BankDtD) of all banks headquartered in a particular country. For a detailed description of the calculation methodology, see Singh et al. (2015). DtD can be interpreted as the number of standard deviations the asset value of the bank is away from the debt threshold. The closer it is to zero, the closer the firm is to distress.

The sample selection methodology is as follows. First, an exhaustive list of all listed and delisted monetary financial institutions is selected from the Bankscope ${ }^{3}$ database. Only banks whose shares were publicly listed and traded between the last quarter of 2004 till the second quarter of 2013 and are headquartered in peripheral euro area countries are selected. Finally, credit institutions which are pure-play insurance, pension or mortgage banks are removed. To formalize this decision, we use Datastream as an additional source of information. The main reason for this exclusion is the difference in liability structure and business model compared to banks. However, this doesn't mean that they are less risky to

\footnotetext{
${ }^{3}$ It provides a comprehensive balance sheet data for financial companies.
} 
the financial system. The market-based data include daily observations of risk-free interest rates, daily stock price and total outstanding share in public. For our analysis, we compute $D t D$ at the quarterly frequency. The variables and data sources are summarized in Table 2, while Table 3 lists the name of banks considered in the analysis.

[Table 2 about here.]

[Table 3 about here.]

Computation of individual DtD: DtD is not measured directly; it is recovered implicitly from the balance sheet and market price of a firm's liabilities. In practical terms, this means that the balance sheet information has to be modified from its original quarterly, half-yearly, or in rare cases, yearly frequencies using cubic spline interpolation. In addition, the real debt contracts are not all written with a single terminal date. To overcome this problem, a common procedure used by Moody's KMV (Vasicek (1984)), and also applied here, is to adopt a one-year horizon $(T=1)$, but to weight longer-term debt (maturity $>1$ year) at only $50 \%$ of face value. The debt barrier $(D)$ will then be equal to the face value of short-term liabilities plus half of the long-term liabilities. The equity value of the firm $(E)$ is computed as the quarterly average of daily market capitalization (number of common shares $\times$ share prices) while quarterly historical volatility based on daily log-returns is taken as equity volatility $\left(\sigma_{E}\right)$. The individual $D t D$ is then calculated using the procedure outlined in Singh et al. (2015).

\subsubsection{Banks average CDS spreads (BankCDS)}

Based on the derivatives market, we use banks 5-year CDS daily mid-quotes from Datastream for all banks headquartered in the five peripheral euro area economies, namely Greece, Ireland, Italy, Portugal, and Spain. Following previous studies, we focus on the 5-year maturity for senior unsecured debt, as these contracts are regarded as the most liquid in the market. The time series of bank CDS spreads for each country was created by averaging individual bank CDS spreads at the country level. We have an overall sample of 25 banks spread across the five countries for which CDS data were available in Datastream (see Table $4)$.

[Table 4 about here.]

\subsubsection{Banks equity index based on average returns (BankEQU)}

Based on the secondary market, we use the country-wise banking sector equity index. The index is based on average logarithmic returns of all publicly traded banking firms' headquartered in a particular country (for the list of banks, please refer to Table 3). The indices are normalized to 100 (at the beginning of the last quarter in 2004) for all countries. ${ }^{4}$

\footnotetext{
${ }^{4}$ Note that the methodology creates an upward bias in the returns indices due to bank failures, and must be interpreted carefully. All the result documented in this paper are based on this unbalanced panel. However, our results are robust to the balanced panel of banks where we only consider banks for which data is available for the entire period.
} 


\subsubsection{Commonality and differences among banking sector risk measures}

Our sample contains Greek, Irish, Italian, Portuguese and Spanish banks. We use quarterly data from 2004-Q4 to 2013-Q2 (i.e., $T=35$ observations). Table 5 provides summary statistics of all banking sector credit risk measures. The mean BankDtD ranges from 2.35 for Greece to 4.58 for Spain. The highest variation is observed for Portugal and Ireland, whereas Greece shows a consistently low level. The median values for Greece and Ireland are 1.87 and 1.75, reflecting the precarious banking conditions in these countries for our time period of study.

\section{[Table 5 about here.]}

The mean value of BankCDS for individual countries are lowest in case of Italy $(1.48 \%)$ and highest in case of Greece (9.64\%). We also observe extremely high values for Greece $(24 \%)$, Ireland $(20 \%)$ and Portugal $(13.65 \%)$. These peaks coincide the period when the banking crisis was at its highest point (as in the case of Ireland) or when the sovereign government in these countries lost market access for issuing new government bonds (as in Greece and Portugal). Also noteworthy is the fact that Irish banks' CDS spreads before the crisis were negligible and then shot up within a very short period of time during the crisis. If we compare this with the BankEQU, we find a similar trend for Ireland. The BankEQU for Spain and Greece also shows huge gains before the crisis compared with Ireland, Italy, and Portugal. Post-crisis, however, the Irish and Greek banking sectors show continuous sign of stress with very low index values.

To study the commonality in different banking sector risk indicators, we compute the cross-country correlations matrix for each alternative indicator. Since the time series of observations are not always of equal length, the correlation between each pair of banking sector risk indicators is based on the common sample. The correlations matrices are shown in Table 6. To evaluate these results, we use the adjective 'strong' for estimated values included in the interval $(2 \mathrm{c}, 1]$, the adjective 'weak' for estimated values included in the interval $(c, 2 c]$, and when the estimated values are included in the interval $(0, c]$, we say that the series is 'not correlated'. The cut-off point $\mathrm{c}$ is chosen because it roughly corresponds to the null hypothesis that the correlation coefficient is zero at $5 \%$ level of significance. ${ }^{5}$

[Table 6 about here.]

As can be seen, there is evidence of a strong positive correlation between the BankDtD indicators. Regarding the BankCDS, we also find a strong positive correlation, except for the case of Ireland with Greece. Finally, and in relation to the BankEQU, we observe a strong positive association between Greece and Italy, a weak positive correlation in Spain with Greece, Italy, and Portugal, in Portugal with Greece and Ireland, and between Portugal and Italy. There is no significant evidence of a correlation between Ireland and Greece, Spain or

\footnotetext{
${ }^{5}$ The standard error is approximately $T^{-1 / 2}, T$ being the sample size. In our case, $T=35$ for BankDtD and BankEQU and $T=22$ for BankCDS. Thus the two standard errors would be 0.34 and 0.43 respectively.
} 
Italy. The highest pair-wise correlations are between BankCDS indices followed by BankDtD and BankEQU. The average pair-wise correlations are above 0.85 for BankCDS which comes down to 0.78 for BankDtD. However, the pair-wise correlation in case of BankEQU is extremely low. We even find a negative correlation between the Spanish and Irish BankEQU.

\subsection{Sovereign risk measures}

To assess the sovereign credit risk, we also use three different risk measures. Our primary measure of credit risk is the sovereign DtD indicator as suggested in Singh et al. (2018). We also use sovereign yield spreads (based on secondary capital market) and sovereign CDS spreads (from the derivative market). The rest of the section describes the sovereign credit risk measures in detail.

\subsubsection{Sovereign distance-to-default (SovDtD)}

Incorporating lessons from the sovereign debt crises in general and from the Greek debt restructuring in particular, we define the priority structure of sovereigns' creditors that is most relevant for peripheral euro-area countries in severe crisis episodes. The basic idea is that even though de jure there is no explicit seniority to a particular group of creditors, almost all market participants expect multilateral creditors' holdings to be senior to private markets. Rating agencies' downgrade of euro area countries during the sovereign debt crisis were also explicitly motivated by seniority issues (see Steinkamp and Westermann (2014)). The Greek debt restructuring of 2012 also validated this differentiation where we observe asymmetrical losses across creditors and across debt instruments based on the seniority of creditors and maturity of different bonds (see, e.g., Zettelmeyer et al. (2013)). Thus, tranching of the sovereign default risk for creditors based on their seniority pushes the market-based measures of credit risk gradually towards the riskiness of junior claim holders.

We exploit this market development to define the priority structure of sovereign creditors based on their place of residence and institutional classification. This classification is used to define two kinds of sovereign liabilities: senior and junior claims holders. Giving legitimacy to the current bankruptcy proceedings where the bankrupt entity formally surrenders its assets to its creditors and sale proceedings are divided among creditors based on the priority structure of liabilities, we price the junior claims as a call option on the sovereign's assets. To this end, we use the market value of sovereign debt in the hands of junior creditors as the equity value. The value of junior claims is calculated by multiplying the market value of the sovereign's total debt with the fraction of the total debt in the hands of junior creditors. The volatility of the sovereign bond price as provided by the $\mathrm{CNMV}^{6}$ is taken as the direct measure of the junior claims volatility. To calculate the default barrier (strike price in case of call option), we use the sum of the general government's short-term debt (where the payment is due in one year or less in nominal terms) and half of the long-term debt.

\footnotetext{
${ }^{6}$ We use data from the National Securities Market Commission (Comisión Nacional del Mercado de Valores (CNMV)), the agency responsible for the financial regulation of the securities markets in Spain. These are daily data on bond market volatility which is calculated as the annualized standard deviation of daily changes in 40-day sovereign bond prices. The quarterly value is then computed as the average of the last three months daily volatility.
} 
An implied value of sovereign assets and its volatility are then estimated using the contingent claims methodology. We calculate a quarterly time series of the SovDtD for Greece, Ireland, Italy, Portugal and Spain. For a detailed description of the methodology, refer to Singh et al. (2018). SovDtD can be interpreted as the number of standard deviation the sovereign's assets value are away from its debt obligations. Figure 3 shows the evolution of SovDtD and BankDtD for each country considered in our analysis.

[Figure 3 about here.]

\subsubsection{Sovereign $C D S$ spreads (SovCDS)}

We use five-year benchmark sovereign CDS daily mid-quotes from Datastream as the second measure of sovereign credit risk (SovCDS). These data are available starting at 2007Q4. Following previous studies we focus on the 5-year maturity, as these contracts are regarded as the most liquid in the market. Figure 2 shows the evolution of SovCDS and BankCDS for each country considered in our analysis.

\subsubsection{Sovereign yield spreads (SovSPR)}

To calculate yield spreads for individual countries (SovSPR), we use the Maastricht criterion bond yields (the long-term interest rates). These are the rates used as a convergence criterion for the European Economic and Monetary Union (EMU) countries, based on the Maastricht Treaty. The series relates to interest rates on long-term government bonds denominated in national currencies. The data are based on central government bond yields on the secondary market, gross of tax, with a residual maturity of around 10 years. Yield spreads are calculated as the difference between the ten-year benchmark sovereign bond yield of each individual country and that of Germany. Figure 4 shows the evolution of SovSPR and BankEQU for each country considered in our analysis.

[Figure 4 about here.]

\subsubsection{Commonality and differences among sovereign credit risk measures}

Our sample contains Greece, Ireland, Italy, Portugal and Spain and we use quarterly data from 2004-Q4 to 2013-Q2. Table 7 provides summary statistics of all sovereign credit risk measures. The mean SovDtD ranges from 10.94 for Portugal to 18.88 for Italy. The highest variation is observed for Ireland and the lowest for Portugal. A closer look at the data shows consistently low values for Portugal, suggesting its vulnerability for our entire period of study. The minimum value is observed for Greece at 1.43.

\section{[Table 7 about here.]}

Comparing this with SovCDS, we find similar trends. If we look at the minimum values for Spain (0.19\%), Greece (0.20\%), Italy (0.20\%) and Portugal (0.29\%), it suggests that before the crisis financial markets priced the default risk of all peripheral sovereign on a par with other central European countries. However, with the advent of the sovereign debt crisis, Greece, Portugal, and Ireland show consistently high CDS spreads (7.94\%, 2.86\%, and 
$2.71 \%$ respectively) compared with Spain and Italy. For Greece, Ireland, and Portugal, we observe huge spikes in CDS spreads coinciding with there loss of market access. For Greece, since it formally restructured its sovereign debt in 2012, we find consistently high values. Looking at yield spreads, we find very low levels for countries before the crisis (Ireland has negative yield spreads for some periods). However, during the crisis, the levels shot up for Greece $(26.51 \%)$ and Portugal $(11.18 \%$ ) creating a vicious loop in which high debt cost made the debt unsustainable, thus increasing the cost of debt further. We see a similar trend for Spain $(5.29 \%)$ and Italy $(4.88 \%)$, but with a less dramatic increase in yield spreads.

To study the commonality between the different sovereign risk measures under study, we compute the cross-country correlations matrix for each alternative indicator. Since the time series of the observations are not always of equal length, the correlation between each sovereign risk indicator is based on the common sample. The correlations matrices are shown in Table 8. As above, we use the adjective 'strong' for estimated values included in the interval $(2 \mathrm{c}, 1]$, the adjective 'weak' for estimated values included in the interval (c,2c] and, when the estimated values are included in the interval $(0, \mathrm{c}]$, we say that the series is 'not correlated'. The cut-off point $\mathrm{c}$ is chosen because it roughly corresponds to the null hypothesis that the correlation coefficient is zero at $5 \%$ level of significance. ${ }^{7}$ As can be seen, we find evidence of a strong positive correlation between the SovDtD indicators in all cases except Italy with Greece and Ireland and Portugal with Ireland and Italy, where we detect high but weak positive correlations. Turning to the SovCDS, we observe a strong and high positive correlation between Italy and Spain, but a weak positive correlation for all other cases except for the pair Greece and Ireland, where no significant correlation is found. Finally, and with respect to the SovSPR, we observe a strong positive association in all cases.

\section{[Table 8 about here.]}

\subsection{Cross-correlations between sovereign and banking sector risk}

To study the commonality between sovereign and banking sector risk indicators, we compute the cross-country correlations matrix for each peripheral euro area country under study. Since the time series of observations are not always of equal length, the correlation between each sovereign risk indicator is based on the common sample. The correlations matrices are shown in Table $9 .{ }^{8}$ Focusing only on the association between the bank and sovereign indicators, we find evidence of a weak negative correlation between BankDtD and SovCDS and SovSPR in all countries except Spain, where no significant correlation between

\footnotetext{
${ }^{7}$ In our case, $T=19$ for SovCDS, $T=23$ for SovDtD and $T=35$ for SovSPR. Thus the two standard errors would be $0.46,0.43$ and 0.34 respectively.

${ }^{8}$ Once again, we use the adjective 'strong' for estimated values included in the interval $(2 \mathrm{c}, 1]$, the adjective 'weak' for estimated values included in the interval $(c, 2 c]$ and, when the estimated values are included in the interval $(0, c]$, we say that the series is 'not correlated'. The cut-off point $c$ is chosen because it roughly corresponds to the null hypothesis that the correlation coefficient is zero at $5 \%$ level of significance. In our case, $T=22$ for Greece, $T=19$ for Ireland and $T=23$ for Italy, Portugal, and Spain. Thus the two standard errors would be $0.43,0.46$ and 0.42 , respectively.
} 
them is found. There is also evidence of strong negative (Italy and Spain) or high but weak negative correlation (in the remaining countries) between BankEQU and SovCDS.

\section{[Table 9 about here.]}

In the case of Greece, we also observe strong positive correlations between BankCDS and SovSPR and between BankEQU and SovCDS, Italy and Spain, as well as a high but weak positive correlation between BankCDS and SovCDS and between BankDtD and SovDtD and a high but weak negative correlation between BankEQU and SovSPR. For Ireland, we also observe a strong positive correlation between BankCDS and SovCDS and a weak positive correlation between BankDtD and SovDtD and between BankCDS and SovSPR, while no significant correlation is found between BankEQU and either SovDtD or SovSPR. In the case of Italy, we also detect strong positive correlations between BankCDS and both SovCDS and SovSPR, as well as a high but weak positive correlation between BankDtD and SovDtD and between SovDtD and SovSPR, and a strong negative correlation between BankEQU and SovSPR. Finally, for Spain, we also observe a strong positive correlation between BankCDS and both SovCDS and SovSPR and a strong negative correlation between BankEQU and SovSPR, while no significant correlation is found between BankDtD and either SovCDS or SovDtD or SovSPR.

\section{Methodology: Assessing interconnection}

We use several econometric techniques to assess the interconnection between the banking sector and sovereign credit risk indicators without modelling the details of the entire network structure. We show that just by including the banks and sovereign credit risk indicators, one can disentangle the inherent contagiousness and vulnerability of the interdependent structure. We use three different sets of indicators for comparison. BankDtD and SovDtD are our primary indicators. The detailed presentation of our results is based on these primary indicators which take into account both the market and balance sheet based information. For comparison, we use secondary market indicators - SovSPR and BankEQU, together with derivative markets measures - SovCDS and BankCDS - for each individual country. An increase in interdependence across all markets will be considered as a robust estimate of our interconnection measures.

\subsection{Principal component analysis}

To measure the commonality among the sovereign and banking sector credit risk indices, we use Principal Component Analysis (PCA), a technique in which the credit risk of all institutions (individual sovereigns and their banking sector) is decomposed into orthogonal factors of decreasing explanatory power (refer to Muirhead (1982) for detailed exposition). We follow Billio et al. (2012). More formally, let $C_{i}$ be the credit risk of institution $i$, $i=1,2,3, . ., N$. Let $E\left[C_{i}\right]=\mu_{i}$ and $\operatorname{Var}\left[C_{i}\right]=\sigma_{i}$, then the variance of the system $\sigma_{S}$ will be, 


$$
\sigma_{S}^{2}=\sum_{i=1}^{N} \sum_{j=1}^{N} \sigma_{i} \sigma_{j} E\left[R_{i} R_{j}\right]
$$

where, $R_{k}$ is the standardized credit risk of institution $k$ given by $R_{k} \equiv\left(C_{k}-\mu_{k}\right) / \sigma_{k}$ for $k=i, j$. We now introduce $N$ zero-mean uncorrelated variables $\zeta_{k}$ for which,

$$
E\left[\zeta_{k} \zeta_{l}\right]= \begin{cases}\lambda_{k}, & \text { if } k=l \\ 0, & \text { if } k \neq l\end{cases}
$$

and all the higher order co-movements are equal to those of $R_{i}$ 's, where $\lambda_{k}$ is the k-th eigenvalue. We express the $R_{i}$ 's as a linear combination of the $\zeta_{k}$ 's

$$
R_{i}=\sum_{k=1}^{N} L_{i k} \zeta_{k}
$$

where $L_{i k}$ represents the factor loadings for $\zeta_{k}$ for an institution $i$. Thus, we have

$$
\begin{gathered}
E\left[R_{i} R_{j}\right]=\sum_{k=1}^{N} \sum_{l=1}^{N} L_{i k} L_{j l} E\left[\zeta_{k}, \zeta_{l}\right]=\sum_{k=1}^{N} L_{i k} L_{j k} \lambda_{k} \\
\sigma_{S}^{2}=\sum_{i=1}^{N} \sum_{j=1}^{N} \sum_{k=1}^{N} \sigma_{i} \sigma_{j} L_{i k} L_{j k} \lambda_{k}
\end{gathered}
$$

PCA yields the decomposition of the variance-covariance matrix of the credit risk measures into the orthogonal matrix of loadings L (eigenvectors of the correlation matrix) and the diagonal matrix of eigenvalues $\Lambda$. Usually, the first few eigenvalues (denoted by $n$ ) explain most of the variation of the system. This subset captures a larger proportion of variations when a majority of credit risk indices move together, as is often associated with stress episodes. Therefore, periods in which few principal components (PCs) explains more than a fraction $H$ of the total variation are indicative of the increase in interconnection.

To classify periods of increasing interdependence, we define $\Omega=\sum_{k=1}^{N} \lambda_{k}$ and $\omega=$ $\sum_{k=1}^{n} \lambda_{k}$ as the total risk of the system and the risk associated with the first $n$ PC respectively. The ratio of the two above values can be defined as "Cumulative Risk Fraction (CRF)" to capture the periods of increased interconnection:

$$
C R F=\frac{\omega}{\Omega}
$$

When the system is highly interconnected, a small number $n$ of $N$ principal components can explain most of the variation in the system. By examining the time variation in the magnitudes of CRF, we will be able to detect increasing correlations between institutions, i.e., increased linkages and integration as well as similarities in risk exposures, which can contribute to systemic risk. We also compute a matrix which calculates the proportion of the variance in each original variable $C_{i}$ accounted for by the first $\mathrm{n}$ factor, which is given by the sum of the squared factor loadings. 


\subsection{Granger causality}

In this subsection, we present two measures of interconnection based on linear Granger causality tests to quantify the magnitude and directionality of linkages between banking and sovereign risk measures. The concept of Granger-causality was introduced by Granger (1969) and Sims (1972) and is widely used to ascertain the importance of the interaction between two series. As is well known, Granger causality is not a relationship between 'causes' and 'effects'. Rather, it is defined in terms of incremental predictive ability (Hoover (2001)): a variable $\mathrm{Y}$ is said to Granger-cause another variable $\mathrm{X}$ if past values of $\mathrm{Y}$ help to predict the current level of $\mathrm{X}$ better than past values of $\mathrm{X}$ alone, indicating that past values of $\mathrm{Y}$ have some informational content that is not present in past values of $\mathrm{X}$. Therefore, knowledge of the evolution of the variable $\mathrm{Y}$ reduces the forecast errors of the variable $\mathrm{X}$, suggesting that $\mathrm{X}$ does not evolve independently of $\mathrm{Y}$.

Tests of Granger causality typically use the same lags for all variables. This poses a potential problem since Granger-causality tests are sensitive to lag length. ${ }^{9}$ In this paper we use Hsiao (1981)'s sequential method to test for causality in order to determine the optimal lag structure for each variable, combining Akaike's final predictive error (FPE, from now on) and the definition of Granger-causality. ${ }^{10}$ Essentially, the FPE criterion trades off the bias that arises from the under-parametrization of a model against a loss in efficiency resulting from its over-parametrization, removing the ambiguities of the conventional procedure.

Consider the following models,

$$
\begin{gathered}
X_{t}=\alpha_{0}+\sum_{i=1}^{m} \delta_{i} X_{t-i}+\epsilon_{t} \\
X_{t}=\alpha_{0}+\sum_{i=1}^{m} \delta_{i} X_{t-i}+\sum_{j=1}^{n} \gamma_{j} Y_{t-j}+\epsilon_{t}
\end{gathered}
$$

where $X_{t}$ and $Y_{t}$ are stationary variables (i.e., they are $\mathrm{I}(0)$ variables). The following steps are used to apply Hsiao's procedure for testing Granger-causality:

1. Treat $X_{t}$ as a one-dimensional autoregressive process (5), and compute its FPE with the order of lags $\mathrm{m}$ varying from 1 to $\mathrm{m}$. Choose the order which yields the smallest FPE, say $m,{ }^{11}$ and denote the corresponding $\mathrm{FPE}_{\text {as }} \mathrm{FPE}_{X}(\mathrm{~m}, 0)$.

2. Treat $X_{t}$ as a controlled variable with m number of lags, and treat $Y_{t}$ as a manipulated variable as in (6). Compute again the FPE of (6) by varying the order of lags of $Y_{t}$

\footnotetext{
${ }^{9}$ The general principle is that shorter lag lengths have smaller variance but run a risk of bias, while longer lags reduce the bias problem but may lead to inefficiency.

${ }^{10}$ Thornton and Batten (1985) show that Akaike's FPE criterion performs well relative to other statistical techniques.

${ }^{11} F P E_{X}(m, 0)$ is computed using the formula: $F P E_{X}(m, 0)=\frac{(T+m+1) S S R}{(T-m-1) T}$ where $\mathrm{T}$ is the total number of observations and SSR is the sum of squared residuals of OLS regression (5).
} 
from 1 to $\mathrm{n}$, and determine the order which gives the smallest FPE, say $\mathrm{n}$, and denote the corresponding FPE as $\operatorname{FPE}_{X}(\mathrm{~m}, \mathrm{n}) .{ }^{12}$

3. Compare $\mathrm{FPE}_{X}(\mathrm{~m}, 0)$ with $\mathrm{FPE}_{X}(\mathrm{~m}, \mathrm{n})$ (i.e., compare the smallest FPE in step 1 with the smallest FPE in step 2). If $\mathrm{FPE}_{X}(\mathrm{~m}, 0)>\mathrm{FPE}_{X}(\mathrm{~m}, \mathrm{n})$, then $Y_{t}$ is said to cause $X_{t}$. If $\mathrm{FPE}_{X}(\mathrm{~m}, 0)<\mathrm{FPE}_{X}(\mathrm{~m}, \mathrm{n})$, then $X_{t}$ is an independent process.

4. Repeat steps 1 to 2 for the $Y_{t}$ variable, treating $X_{t}$ as the manipulated variable.

When $X_{t}$ and $Y_{t}$ are not stationary variables, but are first-difference stationary (i.e., they are I(1) variables) and cointegrated (see Dolado et al. (1990)), it is possible to investigate the existence of Granger-causal relationships from $\Delta X_{t}$ to $\Delta Y_{t}$ and from $\Delta Y_{t}$ to $\Delta X_{t}$, using the following error correction models:

$$
\begin{gathered}
\Delta X_{t}=\alpha_{0}+\sum_{i=1}^{m} \delta_{i} \Delta X_{t-i}+\epsilon_{t} \\
\Delta X_{t}=\alpha_{0}+\beta Z_{t-1}+\sum_{i=1}^{m} \delta_{i} \Delta X_{t-i}+\sum_{j=1}^{n} \gamma_{j} \Delta Y_{t-j}+\epsilon_{t}
\end{gathered}
$$

where $Z_{t}$ is the OLS residual of the cointegrating regression $\left(X_{t}=\mu+\lambda Y_{t}\right)$, known as the error-correction term. Note that, if $X_{t}$ and $Y_{t}$ are $\mathrm{I}(1)$ variables but are not cointegrated, then $\beta$ in (8) is assumed to be equal to zero.

In both cases (i.e., $X_{t}$ and $Y_{t}$ are $\mathrm{I}(1)$ variables, and they are or are not cointegrated), we can use Hsiao's sequential procedure substituting $X_{t}$ with $\Delta X_{t}$ and $Y_{t}$ with $\Delta Y_{t}$ in steps 1 to 4), as well as substituting expressions (5) and (6) with equations (7) and (8). Proceeding in this way, we ensure efficiency since the system is congruent and encompassing (Hendry and Mizon (1999)).

Once the directionality of Granger causal linkage is established, we define the following measure of causality:

$$
Y \rightarrow X= \begin{cases}1, & \text { if Y Granger causes X } \\ 0, & \text { otherwise }\end{cases}
$$

and define $Y \rightarrow Y \equiv 0$. This measure is then used to define the network-based measure of interconnection between the $N$ banking and sovereign risk indicators. We define the Degree of Granger Causality (DGC) for a risk indicator as the fraction of statistically significant Granger-causality linkages with the rest $(N-1)$ of the risk indicators. For example, if the banking sector risk indicator of Italy Granger causes $m$ other risk indicators in our sample, then $\mathrm{DGC}=(m /(N-1))$.

\footnotetext{
${ }^{12} F P E_{X}(m, n)$ is computed using the formula: $F P E_{X}(m, n)=\frac{(T+m+n+1) S S R}{(T-m-n-1) T}$ where $\mathrm{T}$ is the total number of observations and SSR is the sum of squared residuals of OLS regression (6).
} 


\subsection{Diebold-Yilmaz's connectedness measure}

To explore further the systemic underlying component among various credit risk indices, we use the VAR (vector auto regression) methodology based measure of connectedness proposed by Diebold-Yilmaz. The connectedness is based on the decomposition of the forecast error variance, which is briefly described here. For a multivariate time series, the forecast error variance decomposition works as follows: first, we fit a standard VAR model to the series; secondly, using series data up to and including time $t$, we establish an $H$ period ahead forecast (up to time $t+H$ ); and finally, we decompose the forecast error variance for each component with respect to shocks from the same or other components at time $t$.

Consider an N-dimensional covariance-stationary data-generating process (DGP) with orthogonal shocks:

$$
x_{t}=\Theta(L) u_{t}, \quad \Theta(L)=\Theta_{0}+\Theta_{1} L+\Theta_{2} L^{2}+\ldots, \quad E\left(u_{t}, u_{t}^{\prime}\right)=I
$$

Note that $\Theta_{0}$ need not be diagonal. All aspects of connectedness are contained in this very general representation. Contemporaneous aspects of connectedness are summarized in $\Theta_{0}$ and dynamic aspects in $\Theta_{1}, \Theta_{2}, \ldots$ Transformation of $\Theta_{1}, \Theta_{2}, \ldots$ via variance decompositions is needed to reveal and compactly summarize connectedness. Let us denote by $d_{i j}^{H}$ the $i j$-th $H$-step variance decomposition component (i.e., the fraction of variable $i$ 's $H$-step forecast error variance due to shocks in variable $j$ ). The connectedness measures are based on the "non-own", or "cross", variance decompositions, $d_{i j}^{H}, i, j=1, \ldots, N, i \neq j$.

Diebold and Yilmaz (2014) propose several connectedness measures built from pieces of variance decompositions in which the forecast error variance of variable $i$ is decomposed into parts attributed to the various variables in the system. Here we provide a snapshot of their connectedness index. They propose a connectedness table such as Table 10 to understand the various connectedness measures and their relationships. Its main upper-left $N \mathrm{x} N$ block, which contains the variance decompositions, is called the "variance decomposition matrix," and is denoted by $D^{H}=\left[d_{i j}\right]$. The connectedness table increases $D^{H}$ with a rightmost column containing row sums, a bottom row containing column sums, and a bottom-right element containing the grand average, in all cases for $i \neq j$.

[Table 10 about here.]

The off-diagonal entries of $D^{H}$ are the parts of the $N$ forecast-error variance decompositions of relevance from a connectedness perspective. In particular, the gross pairwise directional connectedness from $j$ to $i$ is defined as follows:

$$
C_{i \leftarrow j}^{H}=d_{i j}^{H}
$$

Since in general $C_{i \leftarrow j}^{H} \neq C_{j \leftarrow i}^{H}$ the net pairwise directional connectedness from $j$ to $i$, can be defined as:

$$
C_{i j}^{H}=C_{j \leftarrow i}^{H}-C_{i \leftarrow j}^{H}
$$


Regarding the off-diagonal row sums in Table 10, they give the share of the $H$-step forecast-error variance of variable $x_{i}$ coming from shocks arising in other variables (all other, as opposed to a single other), while the off-diagonal column sums provide the share of the $H$-step forecast-error variance of variable $x_{i}$ going to shocks arising in other variables. Hence, the off-diagonal row and column sums, labelled "from" and "to" in the connectedness table, offer the total directional connectedness measures. In particular, total directional connectedness from others to $i$ is defined as

$$
C_{i \leftarrow \bullet}^{H}=\sum_{j=1, j \neq i}^{N} d_{i j}^{H}
$$

The total directional connectedness to others from $i$ is defined as

$$
C_{\bullet \leftarrow i}^{H}=\sum_{j=1, j \neq i}^{N} d_{j i}^{H}
$$

We can also define net total directional connectedness as

$$
C_{i}^{H}=C_{\bullet \leftarrow i}^{H}-C_{i \leftarrow \bullet}^{H}
$$

Finally, the grand total of the off-diagonal entries in $D^{H}$ (equivalently, the sum of the "from" column or "to" row) measures total connectedness:

$$
C^{H}=\frac{1}{N} \sum_{i, j=1, j \neq i}^{N} d_{i j}^{H}
$$

For the case of non-orthogonal shocks the variance decompositions are not as easy to calculate as before, because the variance of a weighted sum is not an appropriate sum of variances; in this case methodologies for providing orthogonal innovations like traditional Cholesky-factor identification, may be sensitive to ordering. So, following Diebold and Yilmaz (2014), a generalized VAR decomposition (GVD), invariant to ordering, proposed by Koop et al. (1996) and Pesaran and Shin (1998) will be used. The $H$-step generalized variance decomposition matrix is defined as $D^{g H}=\left[d_{i j}^{g H}\right]$, where

$$
d_{i j}^{g H}=\frac{\sigma_{i j}^{-1} \sum_{h=0}^{H-1}\left(e_{i}^{\prime} \Theta_{h} \sum e_{j}\right)}{\sum_{h=0}^{H-1}\left(e_{i}^{\prime} \Theta_{h} \sum \Theta_{h}^{\prime} e_{j}\right)}
$$

In this case, $e_{j}$ is a vector with $j^{\text {th }}$ element unity and zeros elsewhere, $\Theta_{h}$ is the coefficient matrix in the infinite moving-average representation from VAR, $\sum$ is the covariance matrix of the shock vector in the non-orthogonalized-VAR, $\sigma_{i j}$ being its $j^{\text {th }}$ diagonal element. In this GVD framework, the lack of orthogonality means that the rows of do not have sum unity and, in order to obtain a generalized connectedness index $\tilde{D}^{g}=\left[\tilde{d}_{i j}^{g}\right]$, the following normalization is necessary: $\tilde{d}_{i j}^{g}=\frac{d_{i j}^{g}}{\sum_{j=1}^{N} d_{i j}^{g}}$, where by construction $\sum_{j=1}^{N} \tilde{d}_{i j}^{g}=1$ and $\sum_{i, j=1}^{N} \tilde{d}_{i j}^{g}=N$. 
The matrix $\tilde{D}^{g}=\left[\tilde{d}_{i j}^{g}\right]$ permits us to define concepts similar to the ones defined above for the orthogonal case, that is, total directional connectedness, net total directional connectedness and total connectedness.

\section{Empirical results}

\subsection{Principal components analysis (PCA)}

To measure the commonality between sovereign and banking sector credit risk indices, we apply the PCA methodology as discussed in Section 5. However, since PCA seeks to maximize the variance and so is sensitive to scale differences in the variables, we first normalize the data and work with correlations rather than covariance between the original variables. The explanatory power of the first three PCs are shown in Figure 5. The graph suggests that, on average, the first three PCs explain more than $90 \%$ of the total variation of DtD risk indices at all time periods, but the importance of individual component varies drastically across time.

[Figure 5 about here.]

The first principal component is very dynamic and captures between $43 \%$ to $93 \%$ of the variation in credit risk. Starting from a low level of roughly $45 \%$, it starts to increase rapidly in 2008. We see a very rapid increase in the first half of 2008 , followed by a gradual upward movement till the second quarter of 2009. We observe the highest interconnection between indices in 2009-Q2, when the first PC accounts for roughly $93 \%$ of the total variation. This period coincides with the adverse market development across the global financial markets encompassing both the Lehman Brothers and the AIG defaults, followed by the bailout of the six main Irish banks. Very soon afterwards, Greece declared the true nature of its fiscal deficits. From beginning 2009-Q3, the explanatory power of the first PC started to come down, falling as low as $49 \%$ by the end of 2011. In the last ten quarters, it has stabilized around $57 \%$ with minor variations. However, note that this level is roughly $12 \%$ points higher than its pre-crisis level.

We see a similar trend in the second and third PCs. Most of the gains in the explanatory power of the first PC came from an equal reduction in the explanatory power of second and third PCs. The cumulative explanatory power also increased for the first three component in times of the global financial crisis and together they were able to explain roughly $97 \%$ of the variation at the peak of the crisis. Table 11 tabulates the percentage variation explained by the first three PCs for the full sample, pre-crisis period and crisis period. The choice of pre-crisis and crisis period is exogenous based on previous studies. As can be seen, the first and second components show better explanatory power in the pre-crisis period and explain $90 \%$ of the total variation compared with the crisis period $(72 \%)$. The results are in-line with the findings of Beirne and Fratzscher (2013), who showed that idiosyncratic differences in the economic fundamentals explain a substantially higher share of the movements and cross-country differences in sovereign risk post-2008 crisis than in the pre-crisis period.

[Table 11 about here.] 
Table 12 documents the proportion of the variance in each original variable credit risk index accounted for by the first three factors (calculated as the sum of the squared factor loadings). Comparing the pre-crisis and crisis period, we note that the first PC explained around 10 percent of the variance of each index in the pre-crisis period with very low variation within and across country indices (9\% and 13\%). However, estimates from the crisis period suggest huge variation (1\% to $19 \%$ ) during the crisis period. We find a very similar pattern of variation for the second PC as well. This provides additional evidence of decreasing interconnection in the crisis period.

[Table 12 about here.]

\subsubsection{Comparison with CDS and Yield-Returns}

Comparing this with SovCDS and BankCDS, we observe that CDS spreads are driven across the board with a large underlying factor. On average, the first PC drives more than $80 \%$ of the variation. However, since late 2012, the role of the first PC has decreased and the role of the second PC has grown. This provides suggestive evidence of the increasing role of country fundamentals in credit risk measures in the post-crisis landscape. The trend is also very similar to what we observe in the case of $\mathrm{DtD}$, in which increasing higher weight are given to the second and third PC in total variation. Looking at the interconnection (Part II: Table 12), ${ }^{13}$ the crisis period estimates suggest increasing variation across countries in the explanatory power of first three PCs. This divergence is especially pronounced for Ireland and Greece compared with the rest of the countries in our sample.

[Figure 6 about here.]

For PCA results based on SovSPR and BankEQU, we observe multiple peaks in the explanatory power of the first PC. The first peak is observed in the second half of 2009 (coinciding with the confirmation of irregularities in the Greek public finance statistics) while the second peak coincided with the increasing spreads for Spain and Italy in the second half of 2011 and early 2012. The explanatory power of the first PC rises from roughly $60 \%$ to $90 \%$ at the peaks. The gain in its explanatory power comes at the expense of the second PC, providing suggestive evidence that these indices are extremely prone to market sentiment. Results based on interconnection (Part III: Table 12), suggest that in the pre-crisis period, the explanatory power for the first three PCs is quite consistent across countries. However, in the post-crisis period, we observe high variations, especially for Irish sovereign yield and the Portuguese banking sector.

\subsection{Interconnection based on Granger causality}

\subsubsection{Static Granger-causal relationships}

Regarding the cross-country Granger causality linkages between the sovereign and bank risk indicators, Table 13 presents the computed degrees of Granger causality (DGC). Referring to the DtD indicators, our results for the whole sample suggest that the percentage of

\footnotetext{
${ }^{13}$ Due to data limitations, we have PCA results for sovereign and banking sector CDS spreads for the crisis period only.
} 
statistically significant Granger-causality relationships with the rest of risk indicators ranges from 0 in the cases of BankDtD in Italy and Spain to $44 \%$ and 33\% for BankDtD in Portugal and Greece respectively. As for the SovDtD, the cases of Greece and Portugal stand out (both with a DGC of $22 \%$ ). When evaluating the DGC before and during the crisis, in all cases there is a reduction except for the SovDtD in Greece, Italy, and Portugal.

\section{[Table 13 about here.]}

Turning to the CDS risk indicator, our results for the whole sample indicate a greater degree of Granger causality than with the DtD indicator (except for the cases of SovCDS in Greece and Spain), with values ranging from $11 \%$ for BankCDS in Spain and SovCDS in Portugal to $44 \%$ for both BankCDS and SovCDS in Ireland and for BankCDS in Portugal. Due to limited data availability, we cannot assess the DGC before the crisis, but the results for the crisis period are similar to those in the whole sample, except in the cases of the BankCDS in Italy, Ireland, and Portugal, where reductions are recorded.

Finally, with reference to SovSPR and BankEQU, for the whole sample we find a decrease in the DGC with respect to the DtD indicators in the cases of SovSPR in Greece, Italy and Portugal, and for BankEQU in Spain and SovSPR in Italy, Portugal and Spain. When considering the possible variation of the DGC before and during the crisis, we detect a decline in the cases of SovSPR in Ireland and Spain and BankEQU in Greece, Ireland, and Portugal.

\subsubsection{Dynamic Granger causality linkages}

To understand the time-varying nature of bank-sovereign linkages for individual countries, we adopt an eclectic approach in order to directly investigate changes in the existence and the intensity of causality between banking and sovereign risk. To that end, we apply a dynamic approach to assess the evolving nature of the Granger causal linkages and to detect episodes of significant and transitory increases in the pairwise Granger causal relationships. Thus, we look for episodes with evidence of an enhancement in the information content of one series that significantly improves the explanatory power of the future evolution of the other series, suggesting a strengthening of their interdependence. We associate episodes of Granger-causality intensification with episodes of contagion. ${ }^{14}$ As explained above, since the presence and intensity of Granger-causality may vary over time, we adopt a dynamic analysis to detect episodes of a significant, short-run abrupt increase in the causal linkages.

To summarize, in Figures 7, 8 and 9 we plot the evolution over time of the difference between $F P E(m, 0)$ and FPE $(m, n)$ statistics for each individual country based on different risk measures. These graphs provide us with a view of the dynamic bi-directional influence between sovereign and banking risks for each peripheral euro country and constitute our indicator of causality intensification based on time-varying Granger-causality analysis, since it

\footnotetext{
${ }^{14}$ Using the framework for grading the strength of the Granger-causality relationship proposed by Atukeren (2005), we obtain the same classification of episodes of intensification. Atukeren (2005)'s framework uses Poskitt and Tremayne (2013)'s posterior odds ratio test and Jeffreys (1961)'s Bayesian concept of grades of evidence.
} 
illustrates the changes in the directions and magnitudes over time. In Table 14 we summarize the causality intensification episodes for our full sample period. Note that if the difference is positive and statistically significant at the $1 \%$ level in the case of, say, the banking to sovereign risk relationship, this indicates the existence of a significant, transitory increase in the Granger-causality relationship running from country banking risk towards sovereign risk. Note that in the cases of the banking sector equity index and sovereign yield spreads, we do not detect any causality intensification episodes, either from bank to sovereign or from sovereign to bank.

[Figure 7 about here.]

[Figure 8 about here.]

[Figure 9 about here.]

[Table 14 about here.]

Looking at dynamic Granger causality using DtD data for the case of Greece, we find no evidence of bank-sovereign linkages. We observe complete de-linkage in banking and sovereign stress from the very beginning of our sample period. These results are supported by the evidence of the sovereign yield spread and bank equity index data, where we observe a similar trend. The results of the CDS spreads suggest bank-sovereign linkages developing in late 2011 and early 2012, coinciding with the beginning of Greek debt restructuring episode.

In the case of Ireland, we see growing Granger causal linkage from banks to the sovereign in late 2007 and early 2008. However, in late 2008, we see a sudden reversal with a sharp drop in the interconnection between banks and the sovereign. Given the sudden nature of market events in Ireland, we find no supporting evidence of risk transfer from banks to the sovereign, even with yield spread and bank equity index data. For the late 2011 period, we detect a renewed development of the sovereign to bank nexus in CDS spread data. For Italy, in the pre-crisis period, we find no directional linkages; however, from mid-2009, we see the development of uni-directional linkages from sovereign to banks with multiple peaks in late 2009 and early 2011. The CDS spread based analysis shows no such linkages. Yield spread and banks equity index data suggest complete de-linkage between banks and sovereign risk.

As we have serious data limitations in case of Portugal, our analysis using DtD starts only from the beginning of the global financial crisis. We observe high uni-directional risk transfer from sovereign to banks in late 2008 and mid-2011. The analysis based on CDS spreads suggests the existence of bi-directional linkages in late 2010 and early 2011. The analysis based on yield spreads and bank equity index suggests no linkages for the entire period. For the case of Spain, we observe episodes of risk transfer from banks to the sovereign in late 2009 and early 2010 periods. However, from early 2011, we see evidence of risk transfer from the sovereign to banks. The period of 2010Q2-2012Q1 supports the existence of doom loop between the sovereign and banks. Analysis based on CDS spreads also supports the development of bi-directional sovereign-bank linkages in 2012Q3. However, the yield spread 
and bank equity index based analysis suggests no linkages between banks and sovereign risks.

Comparing results across different risk indices, we find that the analysis based on DtD supports the development of bi-directional sovereign-bank linkages in Spain. In the case of Portugal and Italy, we find uni-directional risk transfer from the sovereign to the banks. Analyses based on CDS spreads suggest a risk transfer mainly from banks to the sovereign for Greece, Portugal, and Spain mainly in late 2010 and early 2011. Only in the case of Ireland do we find evidence of risk transfer from the sovereign to banks (2010Q3). The yield spreads and bank equity returns data support the absence of linkages between banks and sovereigns. Finally, Table 13 shows episodes of causality intensification in both directions for Spain, pointing to an adverse feedback loop between sovereigns and banks and corroborating for this country, the findings of Singh et al. (2016), where a two-way negative feedback between sovereign and banks was also detected using sovereign yield spread and BankDtD data.

\subsection{Diebold-Yilmaz's connectedness index}

In this subsection, we apply Diebold-Yilmaz's methodology for assessing connectedness (Diebold and Yilmaz $(2009,2012,2014)$ ) among various banking and sovereign risk indicators under study. These connectedness measures are based on forecast error variance decompositions from vector auto-regressions. The variance decomposition matrix gives us an intuitively appealing connectedness measure, that is, what percentage of the future uncertainty in variable $i$ results from the shocks in variable $j$.

The full-sample connectedness are presented in Table 15. The $i j^{t h}$ entry of the upper-left $6 \times 6$ submatrix gives the estimated $i j^{\text {th }}$ pair-wise directional connectedness contribution to the forecast error variance of risk indicator $i$ from innovations to risk indicator $j$. Hence, the off-diagonal column sums (labelled "Contribution to others") and row sums (labelled "Contribution from others") give the total directional connectedness to all others from $i$ and from all others to $i$ respectively. The bottom row (labelled "Net contribution from others") gives the difference in total directional connectedness (to-from). Finally, the bottom-right element (in boldface) is total connectedness.

\section{[Table 15 about here.]}

As can be seen, the diagonal elements (own connectedness) are among the largest individual elements in the table, ranging from 18.83\% (SovCDS) to $59.64 \%$ (SovSPR) in the case of Greece, from $14.86 \%$ (BankCDS) to $48.88 \%$ (BankEQU) in the case of Ireland, from $21.55 \%$ (BankEQU) to $40.89 \%$ (BankDtD) in the case of Italy, from $20.71 \%$ (BankEQU) to $44.95 \%$ (SovDtD) in the case of Portugal, and from $14.76 \%$ (BankCDS) to $29.81 \%$ (SovSPR) in the case of Spain. Interestingly, the own connectedness is smaller than most of the total directional connectedness FROM others, reflecting that these indicators are relatively dependent on each other; that is to say, shocks that affect a particular indicator spread on the other indicators.

The total connectedness of the sovereign risk indicators varies between $67.45 \%$ in the case of Ireland (indicating that $32.55 \%$ of the variation is due to idiosyncratic shocks) to 
$78.42 \%$ in Spain (suggesting that $21.58 \%$ of the variation is due to idiosyncratic shocks). This result is in line with the value of $78.30 \%$ obtained by Diebold and Yilmaz (2014) for the total connectedness between US financial institutions, but lower than the value of $97.2 \%$ found by Diebold and Yilmaz (2012) for international financial markets.

Figure 10 plots the country-wise net directional connectedness between various risk indices. The plots suggest that, in the case of Greece, SovSPR and BankCDS are net triggers of shocks while SovDtD and BankEQU are net diffusers of shocks. For Ireland, we find that SovDtD and BankDtD are net receivers of shocks and for Italy, SovDtD, BankDtD, and BankEQU. In the case of Portugal, the sovereign risk indicators (SovCDS and SovSPR) are found to be net transmitters of shocks while SovDtD, BankCDS, and BankEQU are net receivers. Finally, in the case of Spain, our results indicate that SovDtD, BankDtD, and BankCDS are net diffusers of shocks.

[Figure 10 about here.]

Comparing across countries, SovDtDs and BankDtD show the least connectedness with other sovereign and bank risk indicators respectively. This may be suggestive evidence of the different information content of these indicators based on sovereign and bank balance sheet information. All risk measures are well connected in each individual country in our study, suggesting the presence of a common underlying factor. SovSPD turns out to be the best connected among all sovereign and bank risk indices. SovDtD and BankDtD are net receivers in each country, suggesting that the increased risk is being driven away from market-based uncertainty to the idiosyncratic risk factors based on the sovereign and banking sectors balance sheet vulnerabilities.

\section{Concluding remarks}

To understand the nature of the sovereign-bank nexus, in this paper we assess the interconnections and their time-varying nature for peripheral euro-area countries. Firstly, we discuss the nature of these interconnections and the reasons for increasing/decreasing linkages. We then propose three different econometric techniques based on principal component analysis, Granger-causality tests and Diebold-Yilmaz's connectedness indices in order to quantify the directional intensity of the interdependence between banking and sovereign risk measures. Our primary credit risk indicator is a contingent claim model-based distanceto-default measure for banks and sovereigns. However, for comparison, we use two other banking and sovereign risk indicators based on the secondary market (sovereign yield spreads and banking sector equity return) and the derivatives market (banking sector average CDS spreads and sovereign CDS spreads).

Our results suggest strong connectedness and co-movement between country-level banking and sovereign risk indicators. We also find evidence of an increasing role of idiosyncratic risk factors driving the evolution of all risk indices in the post-crisis period, thus supporting the claims by Beirne and Fratzscher (2013) that the sensitivity of financial market participants to fundamental differences increased during the crisis. Country-wise analysis of 
time-varying bi-directional linkages using dynamic Granger-causality suggests the development of a bank-sovereign doom loop in Spain corroborating for this country the findings of Singh et al. (2016). An analysis based on Diebold-Yilmaz's connectedness index shows the continuous presence of SovDtD and BankDtD as net receivers of shocks, suggesting that the increased risk is being driven away from market-based uncertainty to the idiosyncratic risk factors, which are better captured by the contingent claim based $D t D$ indices.

In view of the robust evidence of the bank-sovereign nexus in peripheral euro-area countries, we plan to extend our research with an examination of the determinants of increasing/decreasing linkages based on different channels of interconnection, as discussed in Section 3. As membership of the monetary union can have a considerable influence on the banks' and sovereign credit risk in euro-area countries (see De Grauwe (2012); De Grauwe and Ji (2013), we will explore the role of fiscal support, central bank interventions and banking union in the sovereign-bank nexus.

\section{References}

Acharya, V., Drechsler, I., Schnabl, P., 2014. A pyrrhic victory? Bank bailouts and sovereign credit risk. Journal of Finance 69 (6), 2689-2739.

Acharya, V. V., 2009. A theory of systemic risk and design of prudential bank regulation. Journal of Financial Stability 5, 224-255.

Acharya, V. V., Gale, D., Yorulmazer, T., 2011. Rollover risk and market freezes. Journal of Finance 66, 1177-1209.

Acharya, V. V., Thakor, A., 2016. The dark side of liquidity creation: leverage and systemic risk. Journal of Financial Intermediation 28, 4-21.

Acharya, V. V., Yorulmazer, T., 2008a. Cash-in-the-market pricing and optimal resolution of bank failures. Review of Financial Studies 21, 2705-2742.

Acharya, V. V., Yorulmazer, T., 2008b. Information contagion and bank herding. Journal of Money, Credit and Banking 40, 215-231.

Aghion, P., Bolton, P., Dewatripont, M., 2000. Contagious bank failures in a free banking system. European Economic Review 44, 713-718.

Allen, F., Gale, D., 2004. Financial intermediaries and markets. Econometrica 71, 1023-1061.

Altavilla, C., Pagano, M., Simonelli, S., 2016. Bank exposures and sovereign stress transmission. CEPR Discussion Paper No. DP11269.

Alter, A., Schüler, Y. S., 2012. Credit spread interdependencies of European states and banks during the financial crisis. Journal of Banking and Finance 36 (12), 3444-3468.

Ardagna, S., Caselli, F., 2014. 2014. the political economy of the Greek debt crisis: a tale of two bailouts. American Economic Journal: Macroeconomics 6 (4), 291-323.

Atukeren, E., 2005. Measuring the strength of cointegration and Granger-causality. Applied Economics Letters 37, 1607-1614.

Beirne, J., Fratzscher, M., 2013. The pricing of sovereign risk and contagion during the European sovereign debt crisis. Journal of International Money and Finance 34, 60-82.

Beltratti, A., Stulz, R. M., 2015. Bank sovereign bond holdings, sovereign shock spillovers, and moral hazard during the European crisis. NBER Working Paper No. 21150.

Billio, M., Getmansky, M., Lo, A. W., Pelizzon, L., 2012. Econometric measures of connectedness and systemic risk in the finance and insurance sectors. Journal of Financial Economics 104, 535-539.

Black, F., Scholes, M., 1973. The pricing of options and corporate liabilities. Journal of Political Economy 81 (3), 637-654.

Brunnermeier, M. K., Pedersen, L. H., 2009. Market liquidity and funding liquidity. Review of Financial Studies 22, 2201-2238. 
Chen, Y., 1999. Banking panics: the role of the first-come, first-served rule and information externalities. Journal of Political Economy 107, 946-968.

De Grauwe, P., 2012. The governance of a fragile eurozone. The Australian Economic Review 45 (2), $255-268$.

De Grauwe, P., Ji, Y., 2013. Self-fulfilling crises in the eurozone: an empirical test. Journal of International Money and Finance 34, 15-36.

De Marco, F., Macchiavelli, M., 2016. The political origin of home bias: The case of Europe. Finance and Economics Discussion Series 2016-060. Washington: Board of Governors of the Federal Reserve System, http://dx.doi.org/10.17016/FEDS.2016.060.

Diamond, D. W., Rajan, R. G., 2005. Liquidity shortages and banking crises. Journal of Finance 60, 615-647.

Diebold, F. X., Yilmaz, K., 2009. Measuring financial asset return and volatility spillovers, with application to global equity markets. Economic Journal 119, 158-171.

Diebold, F. X., Yilmaz, K., 2012. Better to give than to receive: Predictive directional measurement of volatility spillovers. International Journal of Forecasting 28, 57-66.

Diebold, F. X., Yilmaz, K., 2014. On the network topology of variance decompositions: Measuring the connectedness of financial firms. Journal of Econometrics 182 (1), 119-134.

Dolado, J. J., Jenkinson, T., Sosvilla-Rivero, S., 1990. Cointegration and unit roots. Journal of Economic Surveys 4 (3), 149-173.

Eisenberg, L., Noe, T. H., 2001. Systemic risk in financial systems. Management Science 47 (2), $236-249$.

Farhi, E., Tirole, J., 2012. Collective moral hazard, maturity mismatch, and systemic bailouts. American Economic Review 102, 60-93.

Farhi, E., Tirole, J., 2017. Deadly embrace: Sovereign and financial balance sheets doom loops. Review of Economic Studies (forthcoming).

Goldstein, M., 1998. The Asian financial crisis causes, cures, and systematic implications. Institute for International Economics, June 1998, Washington D.C.

Gómez-Puig, M., Sosvilla-Rivero, S., Ramos-Herrera, M. C., 2014. An update on emu sovereign yield spread drivers in times of crisis: A panel data analysis. The North American Journal of Economics and Finance 30, $133-153$.

Granger, C. W. J., 1969. Investigating causal relations by econometric models and cross-spectral methods. Econometrica 37 (3), 24-36.

Harada, K., Ito, T., Takahashi, S., 2010. Is the distance to default a good measure in predicting bank failures? Case studies. Working Paper 16182, National Bureau of Economic Research.

Heider, F., Hoerova, M., Holthausen, C., 2015. Liquidity hoarding and interbank market spreads: the role of counterparty risk. Journal of Financial Economics 118, 336-354.

Hendry, D. F., Mizon, G. E., 1999. The pervasiveness of Granger causality in econometrics. In Engle, R. F., White, H. (Eds.) Cointegration, Causality, and Forecasting. A Festsschrift in Honour of Clive W. J. Granger (pp. 102-134). Oxford University Press, Oxford.

Hoover, K. D., 2001. Causality in Macroeconomics. Cambridge University Press, Cambridge.

Horváth, B., Huizinga, H., Ioannidou, V., 2015. Determinants and valuation effects of the home bias in European banks' sovereign debt portfolios. CEPR Discussion Paper No. DP10661.

Hsiao, C., 1981. Autoregressive modelling and money-income causality detection. Journal of Monetary Economics 7 (1), 85-106.

Jeffreys, H., 1961. Theory of probability. $3^{\text {rd }}$ edition, Oxford University Press, London.

Kallestrup, R., Lando, D., Murgoci, A., 2016. Financial sector linkages and the dynamics of bank and sovereign credit spreads. Journal of Empirical Finance 38, 374-393.

Khandani, A. E., Lo, A. W., 2011. What happened to the quants in August 2007? Evidence from factors and transactions data. Journal of Financial Markets 14 (1), 1-46.

Koop, G., Pesaran, M. H., Potter, S. M., 1996. Impulse response analysis in non-linear multivariate models. Journal of Econometrics 74 (1), 119-147.

Merton, R. C., 1974. On the pricing of corporate debt: the risk structure of interest rates. Journal of Finance 29 (2), 449-470.

Muirhead, R. J., 1982. Aspects of multivariate statistical theory. John Wiley and Sons, New York. 
Ongena, S., Popov, A. A., Van Horen, N., 2016. The invisible hand of the government: 'moral suasion' during the European sovereign debt crisis. De Nederlandsche Bank Working Paper No. 505.

Pesaran, M. H., Shin, Y., 1998. Generalized impulse response analysis in linear multivariate models. Economic Letters 58 (1), 17-29.

Poskitt, D. S., Tremayne, A. R., 2013. Determining a portfolio of linear time series models. Biometrika 74, $125-137$.

Sims, C. A., 1972. Money, income, and causality. American Economic Review 62 (4), 540-552.

Singh, M. K., Gómez-Puig, M., Sosvilla-Rivero, S., 2015. Bank risk behavior and connectedness in EMU countries. Journal of International Money and Finance 57, 161-184.

Singh, M. K., Gómez-Puig, M., Sosvilla-Rivero, S., 2016. Sovereign-bank linkages: Quantifying directional intensity of risk transfers in emu countries. Journal of International Money and Finance 63, 137-164.

Singh, M. K., Gómez-Puig, M., Sosvilla-Rivero, S., 2018. Incorporating creditors' seniority in contingent claim models: Application to peripheral euro-area countries. Institut de Recerca en Economia Aplicada (IREA) Working Papers, 2018/03. Universitat de Barcelona.

Steinkamp, S., Westermann, F., 2014. The role of creditor seniority in Europe's sovereign debt crisis. Economic Policy 29 (79), 495-552.

Thornton, D. L., Batten, D. S., 1985. Lag-length selection and tests of Granger causality between money and income. Journal of Money, Credit, and Banking 17 (2), 164-178.

Vasicek, O., 1984. Credit valuation. KMV Corporation, San Francisco.

Zettelmeyer, J., Trebesch, C., Gulati, M., 2013. The Greek debt restructuring: an autopsy. Economic Policy 28 (75), 513-563. 
Table 1: Description of variables

Variable Description $\quad$ Frequency Source

BankDtD Banks average $D t D$ based on the $D t D$ of a sample of banks headquartered in each country. The list of banks used in the calculation are shown in Table 3. For detailed methodology, refer to Singh et al. (2015).

SovDtD Sovereign $D t D$. For detailed methodology, refer to Singh et al. (2018).

BankCDS Banks average CDS based on 5Y bank CDS (on senior unsecured bonds) of all banks headquartered in a particular country for which CDS data is available in Datastream. For a complete list of bank, please refer to Table 4 .

SovCDS $5 \mathrm{Y}$ benchmark CDS spreads for individual countries.

BankEQU Banking sector equity index based on the average returns of all publicly traded banks in each individual country.

SovSPR Difference between the 10 year benchmark yield of a country over Germany.
Quarterly Author's calculation

Quarterly Author's calculation

Quarterly Datastream

Quarterly Datastream

Quarterly Datastream

Quarterly Eurostat

Table 2: Description of variables

\begin{tabular}{lll}
\hline \hline Balance sheet variables & Source \\
\hline $\begin{array}{l}\text { Total assets } \\
\begin{array}{l}\text { Short-term liabilities } \\
\text { Total equity }\end{array}\end{array}$ & $\begin{array}{l}\text { As reported in annual/interim reports } \\
\text { Deposits and short term funding } \\
\text { As reported in annual/interim reports }\end{array}$ & $\begin{array}{l}\text { Bankscope (Code 2025) } \\
\text { Bankscope (Code 2030) } \\
\text { Bankscope (Code 2055) }\end{array}$ \\
Daily market based variables & $\begin{array}{l}\text { Benchmark 10Y bond yield of country } \\
\text { where the bank headquarter is based }\end{array}$ & Thomson Datastream \\
Risk-free interest rate & $\begin{array}{l}\text { Daily closing share price multiplied by } \\
\text { total outstanding share in public }\end{array}$ & Thomson Datastream \\
\hline \hline
\end{tabular}


Table 3: List of banks (by country)

\begin{tabular}{|c|c|c|}
\hline Country & Bank name & ISIN \\
\hline Greece & National Bank of Greece SA & GRS003003019 \\
\hline Greece & Piraeus Bank SA & GRS014003008 \\
\hline Greece & Eurobank Ergasias SA & GRS323003004 \\
\hline Greece & Alpha Bank AE & GRS015013006 \\
\hline Greece & Marfin Investment Group & GRS314003005 \\
\hline Greece & Attica Bank SA-Bank of Attica SA & GRS001003003 \\
\hline Greece & General Bank of Greece SA & GRS002003010 \\
\hline Ireland & Depfa Bank Plc & IE0072559994* \\
\hline Ireland & Irish Bank Resolution Corp. Ltd. & IE00B06H8J93* \\
\hline Ireland & Permanent TSB Plc & IE0004678656* \\
\hline Ireland & Bank of Ireland & IE0030606259 \\
\hline Ireland & Allied Irish Banks plc & IE0000197834 \\
\hline Italy & UniCredit $S p A$ & IT0004781412 \\
\hline Italy & Intesa Sanpaolo & IT0000072618 \\
\hline Italy & Banca Monte dei Paschi di Siena SpA & IT0001334587 \\
\hline Italy & Unione di Banche Italiane Scpa & IT0003487029 \\
\hline Italy & Banco Popolare Società Cooperativa & IT0004231566 \\
\hline Italy & Mediobanca SpA & IT0000062957 \\
\hline Italy & Banca popolare dell'Emilia Romagna & IT0000066123 \\
\hline Italy & Banca Popolare di Milano SCaRL & IT0000064482 \\
\hline Italy & Banca Carige SpA & IT0003211601 \\
\hline Italy & Banca Popolare di Sondrio Societa Cooperativa per Azioni & IT0000784196 \\
\hline Italy & Credito Emiliano SpA-CREDEM & IT0003121677 \\
\hline Italy & Credito Valtellinese Soc Coop & IT0000064516 \\
\hline Italy & Banca popolare dell'Etruria e del Lazio Soc. coop. & IT0004919327 \\
\hline Italy & Credito Bergamasco & IT0000064359 \\
\hline Italy & Banco di Sardegna SpA & IT0001005070 \\
\hline Italy & Banco di Desio e della Brianza SpA & IT0001041000 \\
\hline Italy & Banca Ifis SpA & IT0003188064 \\
\hline Italy & Banca Generali SpA & IT0001031084 \\
\hline Italy & Banca Intermobiliare di Investimenti e Gestioni & IT0000074077 \\
\hline Italy & Banca Popolare di Spoleto SpA & IT0001007209 \\
\hline Italy & Banca Profilo SpA & IT0001073045 \\
\hline Italy & Banca Finnat Euramerica SpA & IT0000088853 \\
\hline Portugal & Montepio Holding SGPS SA & PTFNB0AM0005* \\
\hline Portugal & Banco Comercial Português, SA & PTBCP0AM0007 \\
\hline Portugal & Banco Espirito Santo SA & PTBESOAM0007 \\
\hline Portugal & Banco BPI SA & PTBPI0AM0004 \\
\hline Portugal & BANIF, SA & PTBAF0AM0002 \\
\hline Spain & Banco Bilbao Vizcaya Argentaria SA & ES0113211835 \\
\hline Spain & Banco Santander $S A$ & ES0113900J37 \\
\hline Spain & Caixabank, SA & ES0140609019 \\
\hline Spain & Bankia, SA 7 & ES0113307021 \\
\hline Spain & Banco de Sabadell SA & ES0113860A34 \\
\hline Spain & Banco Popular Espanol SA & ES0113790226 \\
\hline Spain & Caja de Ahorros del Mediterraneo & ES0114400007 \\
\hline Spain & Bankinter SA & ES0113679I37 \\
\hline Spain & Renta 4 Banco, S.A. & ES0173358039 \\
\hline
\end{tabular}

Notes: ISIN stands for the International Securities Identification Number. An asterisk $\left(^{*}\right)$ indicates companies delisted during the study period. SIFI are indicated in italics (based on Bank of International Settlements G-SIBs as of November 2014). 
Table 4: List of banks with CDS spreads available in Datastream (by country)

\begin{tabular}{llr}
\hline \hline & & \\
Country & Bank name & ISIN \\
\hline & & GRS003003019 \\
Greece & National Bank of Greece SA & GRS323003004 \\
Greece & Eurobank Ergasias SA & GRS015013006 \\
Greece & Alpha Bank AE & IE0072559994* \\
Ireland & Depfa Bank Plc & IE00B06H8J93* \\
Ireland & Irish Bank Resolution Corp. Ltd. & IE0004678656* \\
Ireland & Permanent TSB Plc & IE0030606259 \\
Ireland & Bank of Ireland & IE0000197834 \\
Ireland & Allied Irish Banks plc & IT0004781412 \\
Italy & UniCredit SpA & IT0000072618 \\
Italy & Intesa Sanpaolo & IT0001334587 \\
Italy & Banca Monte dei Paschi di Siena SpA & IT0003487029 \\
Italy & Unione di Banche Italiane Scpa & IT0004231566 \\
Italy & Banco Popolare Società Cooperativa & IT0000062957 \\
Italy & Mediobanca SpA & IT0000064482 \\
Italy & Banca Popolare di Milano SCaRL & PTBCP0AM0007 \\
Portugal & Banco Comercial Português, SA & PTBES0AM0007 \\
Portugal & Banco Espirito Santo SA & PTBPI0AM0004 \\
Portugal & Banco BPI SA & ES0113211835 \\
Spain & Banco Bilbao Vizcaya Argentaria SA & ES0113900J37 \\
Spain & Banco Santander SA & ES0140609019 \\
Spain & Caixabank, SA & ES0113860A34 \\
Spain & Banco de Sabadell SA & ES0113790226 \\
Spain & Banco Popular Espanol SA & ES0114400007 \\
Spain & Caja de Ahorros del Mediterraneo & ES0113679I37 \\
Spain & Bankinter SA & \\
& & \\
\hline \hline
\end{tabular}

Notes: ISIN stands for the International Securities Identification Number. An asterisk $\left(^{*}\right)$ indicates companies delisted during the study period. SIFI is indicated in italics (based on Bank of International Settlements G-SIBs as of November 2014). 
Table 5: Summary statistics of banking sector risk measures

\begin{tabular}{|c|c|c|c|c|c|c|c|c|c|}
\hline Country & Mean & $\begin{array}{c}\text { Standard } \\
\text { Deviation }\end{array}$ & Minimum & Median & Maximum & Skewness & Kurtosis & $\mathrm{SE}$ & $\mathrm{N}$ \\
\hline \multicolumn{10}{|c|}{ Average banking sector Distance-to-default measure } \\
\hline Spain & 4.58 & 1.80 & 2.00 & 4.42 & 8.50 & 0.41 & -0.90 & 0.30 & 35 \\
\hline Greece & 2.35 & 1.22 & 0.81 & 1.87 & 5.28 & 0.61 & -0.89 & 0.21 & 35 \\
\hline Ireland & 2.69 & 2.08 & 0.49 & 1.75 & 7.51 & 0.87 & -0.70 & 0.35 & 35 \\
\hline Italy & 4.20 & 1.52 & 1.96 & 3.89 & 7.72 & 0.26 & -1.01 & 0.26 & 35 \\
\hline Portugal & 3.96 & 2.06 & 1.45 & 3.21 & 9.58 & 0.90 & -0.07 & 0.35 & 35 \\
\hline
\end{tabular}

\section{Average banking sector credit default swap (CDS) spreads}

\begin{tabular}{lrrrrrrrrr} 
Spain & 300.94 & 157.74 & 41.99 & 288.76 & 549.46 & 0.11 & -1.30 & 32.89 & 23 \\
Greece & 964.18 & 757.44 & 152.05 & 841.43 & 2400.79 & 0.60 & -1.05 & 161.49 & 22 \\
Ireland & 515.82 & 584.15 & 6.80 & 340.70 & 2025.05 & 1.05 & -0.01 & 98.74 & 35 \\
Italy & 148.74 & 155.76 & 12.87 & 85.43 & 493.92 & 1.03 & -0.36 & 26.33 & 35 \\
Portugal & 306.98 & 383.41 & 14.48 & 99.28 & 1365.38 & 1.20 & 0.23 & 64.81 & 35 \\
\hline
\end{tabular}

Average banking sector equity index level (Assuming index level at 100 as on 31st Dec 2014)

$\begin{array}{lrrrrrrrrr}\text { Spain } & 257.71 & 78.91 & 100.00 & 243.67 & 404.41 & 0.01 & -0.64 & 13.34 & 35 \\ \text { Greece } & 188.69 & 137.56 & 15.52 & 154.56 & 512.95 & 0.68 & -0.51 & 23.25 & 35 \\ \text { Ireland } & 101.39 & 63.93 & 6.72 & 123.86 & 188.40 & -0.31 & -1.53 & 10.81 & 35 \\ \text { Italy } & 128.82 & 42.73 & 67.26 & 120.04 & 219.96 & 0.48 & -0.82 & 7.22 & 35 \\ \text { Portugal } & 145.61 & 61.90 & 49.91 & 125.87 & 271.27 & 0.59 & -0.61 & 10.46 & 35\end{array}$

Notes: The BankDtD is a measure the number of standard deviations the banking sector assets are away from its default barrier. Hence, by construction, this is unitless. BankCDS are measured in basis points. BankEQU are unitless and are in levels. 
Table 6: Correlations between banking sector risk measures

\begin{tabular}{|c|c|c|c|c|c|c|c|c|c|c|c|c|c|c|c|}
\hline & $\mathrm{ES}$ & GR & IR & IT & $\mathrm{PT}$ & $\mathrm{ES}$ & GR & IR & IT & PT & ES & GR & IR & IT & PT \\
\hline & \multicolumn{5}{|c|}{ Average banking sector $D t D$} & \multicolumn{5}{|c|}{ Banks average CDS spreads } & \multicolumn{5}{|c|}{ Banking sector equity index } \\
\hline $\mathrm{ES}$ & 1 & 0.72 & 0.86 & 0.75 & 0.73 & 1 & 0.92 & 0.82 & 0.94 & 0.90 & 1 & 0.65 & -0.34 & 0.37 & 0.44 \\
\hline GR & 0.72 & 1 & 0.84 & 0.81 & 0.88 & 0.92 & 1 & 0.73 & 0.95 & 0.94 & 0.65 & 1 & 0.05 & 0.87 & 0.62 \\
\hline IR & 0.86 & 0.84 & 1 & 0.78 & 0.77 & 0.82 & 0.73 & 1 & 0.80 & 0.91 & -0.34 & 0.05 & 1 & 0.26 & 0.38 \\
\hline IT & 0.75 & 0.81 & 0.78 & 1 & 0.84 & 0.94 & 0.95 & 0.80 & 1 & 0.91 & 0.37 & 0.87 & 0.26 & 1 & 0.67 \\
\hline $\mathrm{PT}$ & 0.73 & 0.88 & 0.77 & 0.84 & 1 & 0.90 & 0.94 & 0.91 & 0.91 & 1 & 0.44 & 0.62 & 0.38 & 0.67 & 1 \\
\hline
\end{tabular}

Table 7: Summary statistics of sovereign risk measures

\begin{tabular}{llllllll}
\hline \hline Country & Mean & $\begin{array}{c}\text { Standard } \\
\text { Deviation }\end{array}$ & Minimum & Median & Maximum Skewness Kurtosis & SE N \\
\hline
\end{tabular}

Sovereign Distance-to-default measure

\begin{tabular}{|c|c|c|c|c|c|c|c|c|c|}
\hline Spain & 17.72 & 7.36 & 5.23 & 17.52 & 32.38 & 0.03 & -1.28 & 1.24 & 35 \\
\hline Greece & 14.39 & 10.12 & 1.43 & 14.25 & 31.85 & 0.11 & -1.59 & 1.71 & 35 \\
\hline Ireland & 17.38 & 8.47 & 3.76 & 16.71 & 35.22 & 0.18 & -1.04 & 1.43 & 35 \\
\hline Italy & 18.88 & 7.54 & 5.73 & 20.25 & 31.39 & -0.30 & -1.13 & 1.27 & 35 \\
\hline Portugal & 10.94 & 6.67 & 2.66 & 9.15 & 23.93 & 0.49 & -1.21 & 1.39 & 23 \\
\hline
\end{tabular}

Five year benchmark Sovereign credit default swap (CDS) spreads

\begin{tabular}{lrrrrrrrrr} 
Spain & 171.86 & 112.55 & 18.79 & 175.41 & 402.16 & 0.37 & -1.02 & 23.47 & 23 \\
Greece & 4411.58 & 6219.48 & 20.32 & 794.91 & 14904.36 & 0.93 & -1.05 & 1296.85 & 23 \\
Ireland & 345.35 & 226.63 & 125.28 & 271.33 & 841.86 & 0.64 & -1.03 & 51.99 & 19 \\
Italy & 168.87 & 118.58 & 19.58 & 141.86 & 415.01 & 0.69 & -0.77 & 24.73 & 23 \\
Portugal & 386.25 & 375.76 & 28.99 & 286.05 & 1170.3 & 0.89 & -0.66 & 80.11 & 22 \\
& & & & & & & & & \\
\hline
\end{tabular}

Sovereign yield spreads over Germany

\begin{tabular}{|c|c|c|c|c|c|c|c|c|c|}
\hline Spain & 1.37 & 1.57 & 0.01 & 0.67 & 5.29 & 0.87 & -0.64 & 0.27 & 35 \\
\hline Greece & 5.60 & 7.16 & 0.19 & 1.86 & 26.52 & 1.21 & 0.40 & 1.21 & 35 \\
\hline Ireland & 2.19 & 2.49 & -0.04 & 1.52 & 8.54 & 0.91 & -0.41 & 0.42 & 35 \\
\hline Italy & 1.43 & 1.40 & 0.14 & 0.85 & 4.88 & 1.03 & -0.23 & 0.24 & 35 \\
\hline Portugal & 2.76 & 3.52 & 0.00 & 0.77 & 11.18 & 1.15 & -0.04 & 0.59 & 35 \\
\hline
\end{tabular}


Table 8: Correlations between different sovereign risk measures

\begin{tabular}{|c|c|c|c|c|c|c|c|c|c|c|c|c|c|c|c|}
\hline & ES & GR & IR & IT & $\mathrm{PT}$ & ES & GR & IR & IT & $\mathrm{PT}$ & ES & GR & IR & IT & $\mathrm{PT}$ \\
\hline & \multicolumn{2}{|c|}{ Sovereign } & DtD & meas & ire & \multicolumn{5}{|c|}{ Sovereign CDS spreads } & \multicolumn{5}{|c|}{ Sovereign yield spread } \\
\hline $\mathrm{ES}$ & 1 & 0.92 & 0.87 & 0.93 & 0.87 & 1 & 0.73 & 0.65 & 0.95 & 0.89 & 1 & 0.96 & 0.80 & 0.96 & 0.91 \\
\hline GR & 0.92 & 1 & 0.87 & 0.81 & 0.91 & 0.73 & 1 & 0.03 & 0.73 & 0.55 & 0.96 & 1 & 0.85 & 0.94 & 0.96 \\
\hline IR & 0.87 & 0.87 & 1 & 0.75 & 0.70 & 0.65 & 0.03 & 1 & 0.58 & 0.82 & 0.80 & 0.85 & 1 & 0.79 & 0.88 \\
\hline IT & 0.93 & 0.81 & 0.75 & 1 & 0.71 & 0.95 & 0.73 & 0.58 & 1 & 0.89 & 0.96 & 0.94 & 0.79 & 1 & 0.93 \\
\hline $\mathrm{PT}$ & 0.87 & 0.91 & 0.70 & 0.71 & 1 & 0.89 & 0.55 & 0.82 & 0.89 & 1 & 0.91 & 0.96 & 0.88 & 0.93 & 1 \\
\hline
\end{tabular}


Table 9: Country-wise cross-correlations between sovereign and banking risk indicators

\begin{tabular}{|c|c|c|c|c|c|c|}
\hline Greece & BankDtD & BankCDS & BankEQU & SovCDS & SovDtD & SovSPR \\
\hline BankDtD & 1 & -0.83 & 0.84 & -0.69 & 0.81 & -0.77 \\
\hline BankCDS & -0.83 & 1 & -0.8 & 0.72 & -0.81 & 0.95 \\
\hline BankEQU & 0.84 & -0.8 & 1 & -0.69 & 0.92 & -0.78 \\
\hline SovCDS & -0.69 & 0.72 & -0.69 & 1 & -0.63 & 0.69 \\
\hline SovDtD & 0.81 & -0.81 & 0.92 & -0.63 & 1 & -0.8 \\
\hline SovSPR & -0.77 & 0.95 & -0.78 & 0.69 & -0.8 & 1 \\
\hline Ireland & BankDtD & BankCDS & BankEQU & SovCDS & SovDtD & SovSPR \\
\hline BankDtD & 1 & 0.03 & 0.67 & -0.19 & 0.5 & -0.05 \\
\hline BankCDS & 0.03 & 1 & 0.3 & 0.91 & -0.59 & 0.9 \\
\hline BankEQU & 0.67 & 0.3 & 1 & 0.18 & 0.21 & 0.15 \\
\hline SovCDS & -0.19 & 0.91 & 0.18 & 1 & -0.72 & 0.92 \\
\hline SovDtD & 0.5 & -0.59 & 0.21 & -0.72 & 1 & -0.67 \\
\hline SovSPR & -0.05 & 0.9 & 0.15 & 0.92 & -0.67 & 1 \\
\hline Italy & BankDtD & BankCDS & BankEQU & SovCDS & SovDtD & SovSPR \\
\hline BankDtD & 1 & -0.43 & 0.42 & -0.47 & 0.61 & -0.44 \\
\hline BankCDS & -0.43 & 1 & -0.83 & 0.96 & -0.84 & 0.98 \\
\hline BankEQU & 0.42 & -0.83 & 1 & -0.83 & 0.72 & -0.84 \\
\hline SovCDS & -0.47 & 0.96 & -0.83 & 1 & -0.83 & 0.97 \\
\hline SovDtD & 0.61 & -0.84 & 0.72 & -0.83 & 1 & -0.82 \\
\hline SovSPR & -0.44 & 0.98 & -0.84 & 0.97 & -0.82 & 1 \\
\hline Portugal & BankDtD & BankCDS & BankEQU & SovCDS & SovDtD & SovSPR \\
\hline BankDtD & 1 & -0.49 & 0.24 & -0.54 & 0.47 & -0.55 \\
\hline BankCDS & -0.49 & 1 & -0.58 & 0.97 & -0.8 & 0.97 \\
\hline BankEQU & 0.24 & -0.58 & 1 & -0.62 & 0.46 & -0.54 \\
\hline SovCDS & -0.54 & 0.97 & -0.62 & 1 & -0.78 & 0.98 \\
\hline SovDtD & 0.47 & -0.8 & 0.46 & -0.78 & 1 & -0.82 \\
\hline SovSPR & -0.55 & 0.97 & -0.54 & 0.98 & -0.82 & 1 \\
\hline Spain & BankDtD & BankCDS & BankEQU & SovCDS & SovDtD & SovSPR \\
\hline BankDtD & 1 & 0.01 & 0.06 & 0.04 & 0.2 & 0.09 \\
\hline BankCDS & 0.01 & 1 & -0.9 & 0.96 & -0.88 & 0.94 \\
\hline BankEQU & 0.06 & -0.9 & 1 & -0.88 & 0.82 & -0.88 \\
\hline SovCDS & 0.04 & 0.96 & -0.88 & 1 & -0.84 & 0.96 \\
\hline SovDtD & 0.2 & -0.88 & 0.82 & -0.84 & 1 & -0.82 \\
\hline SovSPR & 0.09 & 0.94 & -0.88 & 0.96 & -0.82 & 1 \\
\hline
\end{tabular}


Table 10: Schematic connectedness table

\begin{tabular}{cccccc}
\hline \hline & & & & & \\
& $x_{1}$ & $x_{2}$ & $\ldots$ & $x_{N}$ & From others \\
\hline$x_{1}$ & $d_{11}^{H}$ & $d_{12}^{H}$ & $\ldots$ & $d_{1 N}^{H}$ & $\sum_{j=1, j \neq 1}^{N} d_{1 j}^{H}$ \\
$x_{2}$ & $d_{21}^{H}$ & $d_{22}^{H}$ & $\ldots$ & $d_{2 N}^{H}$ & $\sum_{j=1, j \neq 2}^{N} d_{2 j}^{H}$ \\
.. &.. & $\ldots$ &.. &.. & \\
.. &.. & $\ldots$ &.. &.. & $\sum_{j=1, j \neq N}^{N} d_{N j}^{H}$ \\
$x_{N}$ & $d_{N 1}^{H}$ & $d_{N 2}^{H}$ & $\ldots$ & $d_{N N}^{H}$ & \\
\hline & & & & & \\
To others & $\sum_{i=1, i \neq 1}^{N} d_{i 1}^{H}$ & $\sum_{i=1, i \neq 2}^{N} d_{i 2}^{H}$ & & $\sum_{i=1, i \neq N}^{N} d_{i N}^{H}$ & $\frac{1}{N} \sum_{i, j=1, i \neq j}^{N} d_{i j}^{H}$ \\
& & & & & \\
\hline \hline
\end{tabular}

Table 11: Principal component analysis results

\begin{tabular}{|c|c|c|c|c|c|c|}
\hline $\begin{array}{l}\text { Principal } \\
\text { Component }\end{array}$ & $\begin{array}{l}\text { Percentage } \\
\text { Explained }\end{array}$ & Total & $\begin{array}{l}\text { Percentage } \\
\text { Explained }\end{array}$ & Total & $\begin{array}{l}\text { Percentage } \\
\text { Explained }\end{array}$ & Total \\
\hline & \multicolumn{2}{|c|}{ Full sample } & \multicolumn{2}{|c|}{$\begin{array}{l}\text { Pre-crisis period } \\
(2004 Q 4-2008 Q 3)\end{array}$} & \multicolumn{2}{|c|}{$\begin{array}{c}\text { Crisis period } \\
(2008 Q 4-2013 Q 2)\end{array}$} \\
\hline First & 0.7932 & 0.7932 & 0.7226 & 0.7226 & 0.5101 & 0.5101 \\
\hline Second & 0.0833 & 0.8766 & 0.1744 & 0.8970 & 0.2128 & 0.7229 \\
\hline Third & 0.0472 & 0.9238 & 0.0491 & 0.9462 & 0.1302 & 0.8531 \\
\hline
\end{tabular}


Table 12: Connectedness based on principal component analysis

\begin{tabular}{|c|c|c|c|c|c|c|c|c|c|}
\hline \multicolumn{10}{|c|}{ Part I: Based on sovereign DtD and banking sector DtD } \\
\hline \multicolumn{4}{|c|}{ Full-sample } & \multicolumn{3}{|c|}{$\begin{array}{c}\text { Pre-crisis } \\
(\text { 2004Q4-2008Q3) }\end{array}$} & \multicolumn{3}{|c|}{$\begin{array}{c}\text { Crisis period } \\
(2008 Q 4-2013 Q 2)\end{array}$} \\
\hline & PC-1 & PC-1:2 & $\mathrm{PC}-1: 3$ & PC-1 & PC-1:2 & PC-1:3 & $\mathrm{PC}-1$ & PC-1:2 & PC-1:3 \\
\hline BankDtD - Spain & 0.09 & 0.40 & 0.42 & 0.11 & 0.22 & 0.35 & 0.01 & 0.27 & 0.27 \\
\hline SovDtD - Spain & 0.12 & 0.23 & 0.23 & 0.13 & 0.19 & 0.19 & 0.18 & 0.19 & 0.24 \\
\hline BankDtD - Greece & 0.12 & 0.12 & 0.14 & 0.09 & 0.24 & 0.27 & 0.19 & 0.22 & 0.23 \\
\hline SovDtD - Greece & 0.12 & 0.20 & 0.27 & 0.12 & 0.26 & 0.27 & 0.13 & 0.14 & 0.33 \\
\hline BankDtD - Ireland & 0.11 & 0.28 & 0.36 & 0.11 & 0.18 & 0.47 & 0.02 & 0.39 & 0.44 \\
\hline SovDtD - Ireland & 0.11 & 0.13 & 0.44 & 0.12 & 0.25 & 0.26 & 0.02 & 0.31 & 0.52 \\
\hline BankDtD - Italy & 0.11 & 0.14 & 0.46 & 0.13 & 0.18 & 0.18 & 0.09 & 0.11 & 0.53 \\
\hline SovDtD - Italy & 0.10 & 0.35 & 0.42 & 0.10 & 0.30 & 0.30 & 0.19 & 0.19 & 0.19 \\
\hline BankDtD - Portugal & 0.11 & 0.13 & 0.26 & 0.09 & 0.18 & 0.71 & 0.17 & 0.17 & 0.24 \\
\hline \multicolumn{10}{|c|}{ Part II: Based on sovereign CDS and banks average CDS } \\
\hline & \multicolumn{3}{|c|}{ Full-sample } & \multicolumn{3}{|c|}{$\begin{array}{c}\text { Pre-crisis } \\
(\text { 2004Q4-2008Q3) }\end{array}$} & \multicolumn{3}{|c|}{$\begin{array}{c}\text { Crisis period } \\
(2008 \mathrm{Q} 4-2013 \mathrm{Q} 2)\end{array}$} \\
\hline & PC-1 & PC-1:2 & PC-1:3 & $\mathrm{PC}-1$ & PC-1:2 & PC-1:3 & PC-1 & PC-1:2 & PC-1:3 \\
\hline BankCDS - Spain & - & - & - & - & - & - & 0.12 & 0.12 & 0.26 \\
\hline SovCDS - Spain & - & - & - & - & - & - & 0.12 & 0.13 & 0.14 \\
\hline BankCDS - Greece & - & - & - & - & - & - & 0.12 & 0.13 & 0.17 \\
\hline SovCDS - Greece & - & - & - & - & - & - & 0.05 & 0.40 & 0.54 \\
\hline BankCDS - Ireland & - & - & - & - & - & - & 0.07 & 0.27 & 0.65 \\
\hline SovCDS - Ireland & - & - & - & - & - & - & 0.07 & 0.36 & 0.36 \\
\hline BankCDS -Italy & - & - & - & - & - & - & 0.11 & 0.18 & 0.18 \\
\hline SovCDS -Italy & - & - & - & - & - & - & 0.11 & 0.14 & 0.28 \\
\hline BankCDS - Portugal & - & - & - & - & - & - & 0.12 & 0.15 & 0.16 \\
\hline SovCDS - Portugal & - & - & - & - & - & - & 0.11 & 0.13 & 0.25 \\
\hline \multicolumn{10}{|c|}{ Part III: Based on sovereign yield spreads and banking sector equity index } \\
\hline & \multicolumn{3}{|c|}{ Full-sample } & \multicolumn{3}{|c|}{$\begin{array}{c}\text { Pre-crisis } \\
(2004 \mathrm{Q} 4-2008 \mathrm{Q})\end{array}$} & \multicolumn{3}{|c|}{$\begin{array}{c}\text { Crisis period } \\
(2008 \mathrm{Q} 4-2013 \mathrm{Q} 2)\end{array}$} \\
\hline & PC-1 & PC-1:2 & PC-1:3 & $\mathrm{PC}-1$ & PC-1:2 & $\mathrm{PC}-1: 3$ & $\mathrm{PC}-1$ & PC-1:2 & PC-1:3 \\
\hline BankEQU - Spain & 0.01 & 0.58 & 0.58 & 0.12 & 0.18 & 0.26 & 0.12 & 0.15 & 0.25 \\
\hline SovSPR - Spain & 0.14 & 0.15 & 0.20 & 0.14 & 0.17 & 0.17 & 0.13 & 0.13 & 0.14 \\
\hline BankEQU - Greece & 0.11 & 0.23 & 0.24 & 0.10 & 0.20 & 0.33 & 0.12 & 0.14 & 0.19 \\
\hline SovSPR - Greece & 0.14 & 0.16 & 0.19 & 0.13 & 0.17 & 0.33 & 0.12 & 0.16 & 0.16 \\
\hline BankEQU - Ireland & 0.00 & 0.13 & 0.68 & 0.03 & 0.26 & 0.52 & 0.09 & 0.23 & 0.23 \\
\hline SovSPR - Ireland & 0.12 & 0.20 & 0.21 & 0.15 & 0.16 & 0.19 & 0.05 & 0.32 & 0.62 \\
\hline BankEQU - Italy & 0.12 & 0.14 & 0.19 & 0.02 & 0.28 & 0.37 & 0.11 & 0.18 & 0.25 \\
\hline SovSPR - Italy & 0.14 & 0.15 & 0.20 & 0.14 & 0.16 & 0.30 & 0.13 & 0.13 & 0.14 \\
\hline BankEQU - Portugal & 0.07 & 0.11 & 0.33 & 0.03 & 0.27 & 0.31 & 0.02 & 0.40 & 0.83 \\
\hline SovSPR - Portugal & 0.14 & 0.16 & 0.19 & 0.15 & 0.15 & 0.21 & 0.12 & 0.17 & 0.20 \\
\hline
\end{tabular}

Notes: The table documents the proportion of the variance of each individual credit risk index accounted for by the first one, two and three principal component (cumulative) for the full sample, pre-crisis and crisis period respectively. BankDtD and SovDtD represent the average banking sector and sovereign credit risk based on contingent claims analysis as documented in Section 3. The sovereign credit risk of Portugal is only available starting 2007Q3 and so is not included in the calculation. For the sake of comparison, the crisis periods also exclude the Portuguese sovereign credit risk in PCA calculation. BankCDS and SovCDS represent the average banking sector CDS and sovereign CDS as observed in the market. The CDS data for the full sample starts at 2008Q4. Therefore for CDS, we report PCA analysis only for the crisis period. BankEQU and SovSPR represents the average returns based banking sector index and sovereign yield spreads as documented in Section 3. 
Table 13: Degree of Granger causality (DGC) based on static Granger causality linkages

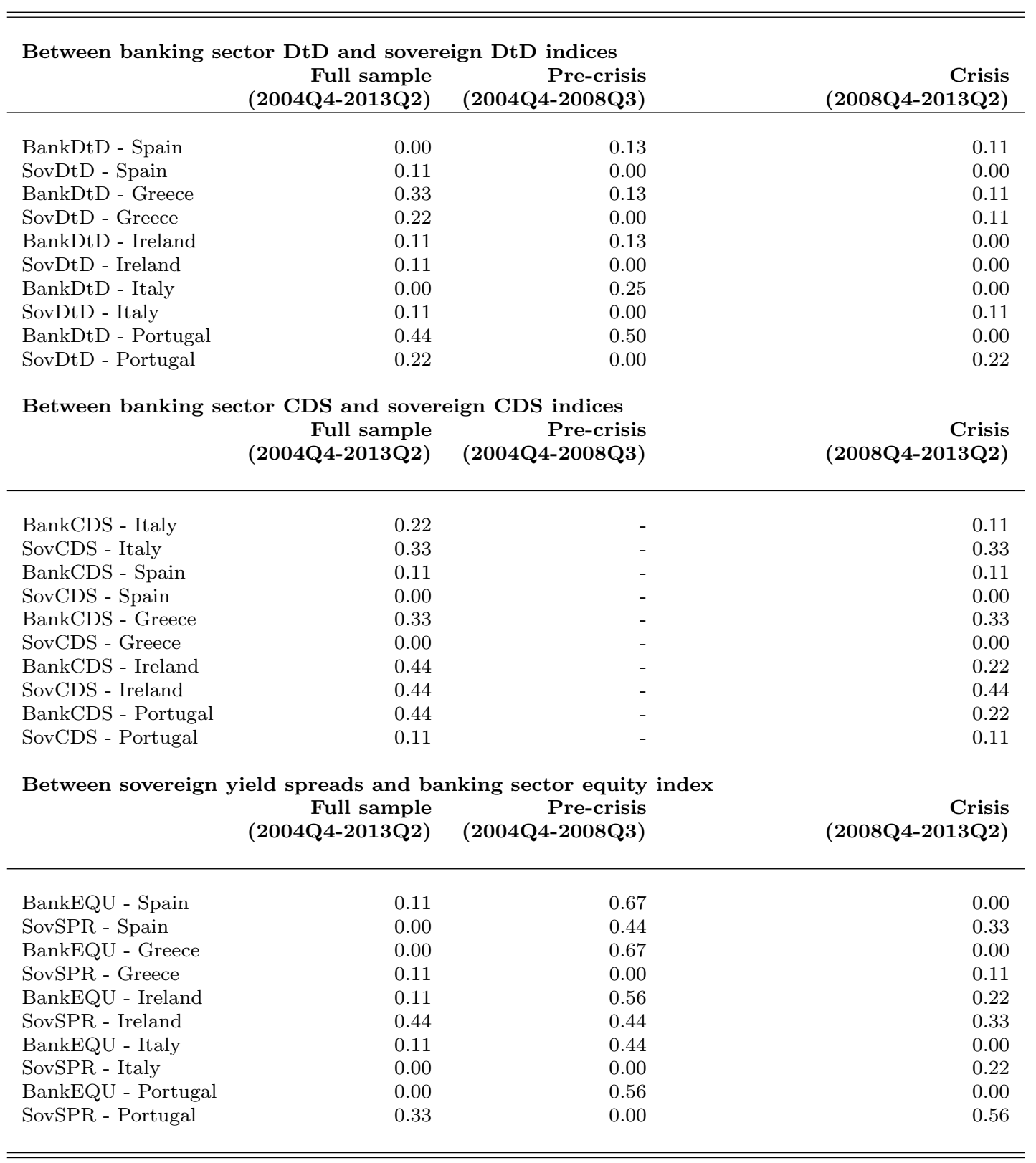

Notes: The numbers represent the Degree of Granger causality (DGC) as discussed in Section 5.2 
Table 14: Episodes of causality intensification

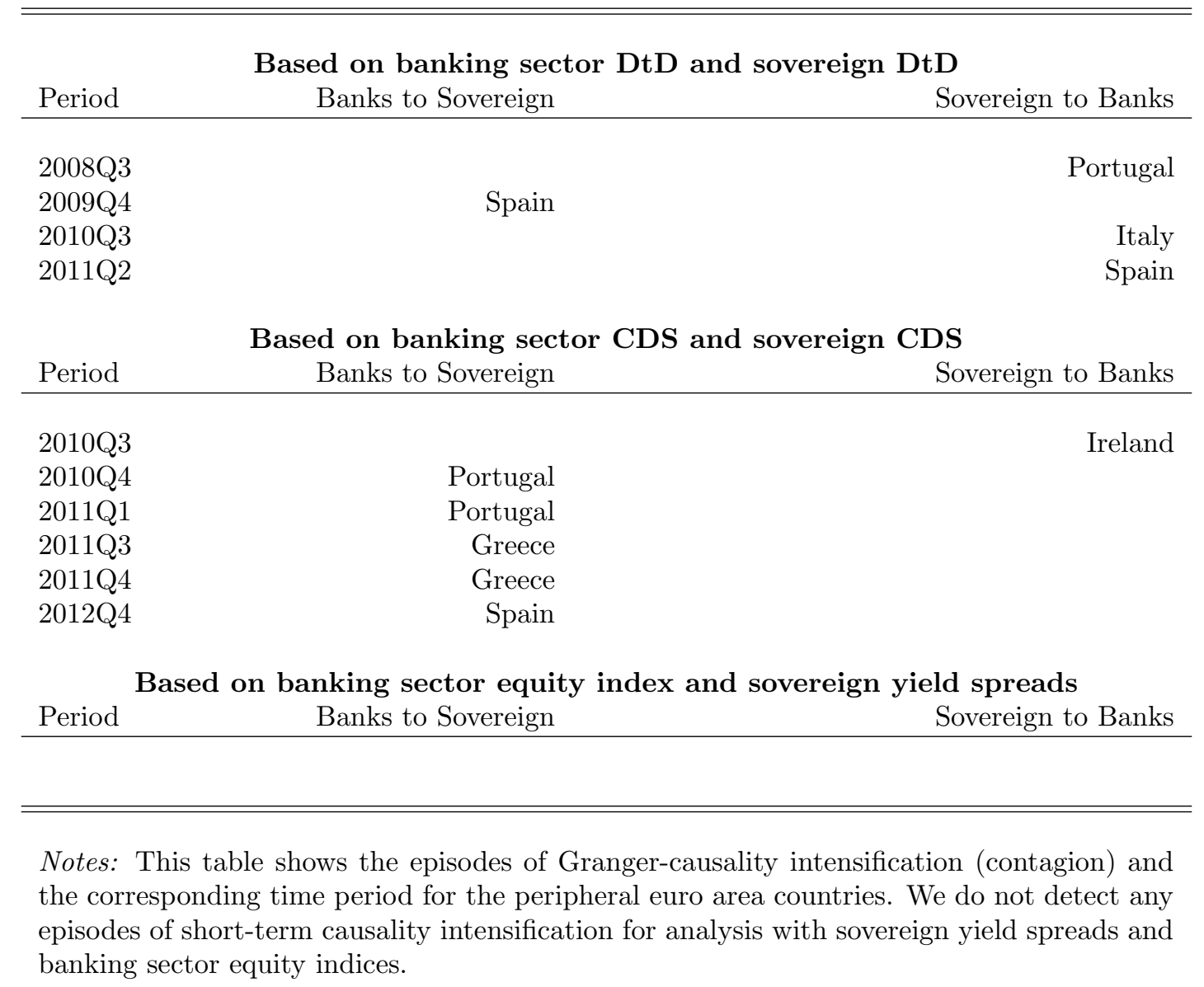


Table 15: Total connectedness between banking and sovereign risk indicators

\begin{tabular}{|c|c|c|c|c|c|c|c|}
\hline Spain & SovDtD & SovCDS & SovSPR & BankDtD & BankCDS & BankEQU & $\begin{array}{r}\text { Contribution } \\
\text { from others }\end{array}$ \\
\hline SovDtD & 14.88 & 21.66 & 23.52 & 11.49 & 11.53 & 16.93 & 85.12 \\
\hline SovCDS & 11.86 & 27.52 & 28.52 & 4.42 & 12.69 & 14.99 & 72.48 \\
\hline SovSPR & 11.92 & 27.35 & 29.81 & 4.64 & 12.41 & 13.88 & 70.19 \\
\hline BankDtD & 10.08 & 16.14 & 23.08 & 21.20 & 15.67 & 13.82 & 78.80 \\
\hline BankCDS & 10.54 & 24.49 & 27.58 & 8.48 & 14.76 & 14.15 & 85.24 \\
\hline BankEQU & 15.53 & 22.85 & 20.91 & 8.41 & 10.98 & 21.33 & 78.67 \\
\hline Contribution to others & 80.11 & 80.35 & 80.57 & 63.84 & 81.09 & 77.58 & \\
\hline Net contribution & -5.01 & 7.86 & 10.38 & -14.96 & -4.16 & -1.10 & Total $=78.42$ \\
\hline Greece & SovDtD & SovCDS & SovSPR & BankDtD & BankCDS & BankEQU & $\begin{array}{r}\text { Contribution } \\
\text { from others }\end{array}$ \\
\hline SovDtD & 24.65 & 8.73 & 20.63 & 8.01 & 12.18 & 25.79 & 75.35 \\
\hline SovCDS & 0.98 & 18.83 & 22.54 & 25.09 & 31.70 & 0.86 & 81.17 \\
\hline SovSPR & 3.64 & 13.00 & 43.06 & 11.33 & 21.05 & 7.92 & 56.94 \\
\hline BankDtD & 5.41 & 19.25 & 19.81 & 26.72 & 26.81 & 2.01 & 73.28 \\
\hline BankCDS & 4.07 & 6.95 & 52.30 & 11.69 & 19.97 & 5.01 & 80.03 \\
\hline BankEQU & 19.04 & 4.85 & 33.02 & 4.61 & 8.83 & 29.65 & 70.35 \\
\hline Contribution to others & 57.34 & 73.70 & 77.50 & 69.45 & 83.43 & 58.38 & \\
\hline Net contribution & -18.01 & -7.46 & 20.56 & -3.83 & 3.40 & -11.97 & Total $=72.85$ \\
\hline Ireland & SovDtD & SovCDS & SovSPR & BankDtD & BankCDS & BankEQU & $\begin{array}{r}\text { Contribution } \\
\text { from others }\end{array}$ \\
\hline SovDtD & 34.41 & 26.39 & 22.58 & 6.00 & 2.34 & 8.29 & 65.59 \\
\hline SovCDS & 12.35 & 29.92 & 28.53 & 14.25 & 3.77 & 11.18 & 70.08 \\
\hline SovSPR & 13.48 & 16.34 & 31.79 & 3.18 & 17.01 & 18.20 & 68.21 \\
\hline BankDtD & 4.01 & 23.13 & 15.79 & 35.44 & 7.33 & 14.28 & 64.56 \\
\hline BankCDS & 8.55 & 20.25 & 29.97 & 8.45 & 14.86 & 17.93 & 85.14 \\
\hline BankEQU & 0.27 & 3.63 & 24.23 & 1.86 & 21.13 & 48.88 & 51.12 \\
\hline Contribution to others & 52.92 & 75.00 & 79.21 & 48.76 & 77.64 & 58.84 & \\
\hline Net contribution & -12.68 & 4.91 & 11.00 & -15.79 & -7.50 & 7.72 & Total $=67.45$ \\
\hline Italy & SovDtD & SovCDS & SovSPR & BankDtD & BankCDS & BankEQU & $\begin{array}{r}\text { Contribution } \\
\text { from others }\end{array}$ \\
\hline SovDtD & 22.67 & 16.37 & 16.08 & 9.96 & 16.88 & 18.04 & 77.33 \\
\hline SovCDS & 7.94 & 24.17 & 24.63 & 3.22 & 24.94 & 15.09 & 75.83 \\
\hline SovSPR & 9.26 & 23.69 & 24.90 & 2.40 & 24.68 & 15.06 & 75.10 \\
\hline BankDtD & 20.32 & 6.91 & 5.09 & 40.89 & 7.04 & 19.75 & 59.11 \\
\hline BankCDS & 8.61 & 23.95 & 24.83 & 2.52 & 25.00 & 15.08 & 75.00 \\
\hline BankEQU & 14.48 & 18.60 & 17.31 & 9.30 & 18.76 & 21.55 & 78.45 \\
\hline Contribution to others & 72.77 & 78.74 & 77.93 & 40.13 & 78.69 & 79.39 & \\
\hline Net contribution & -4.55 & 2.91 & 2.84 & -18.99 & 3.69 & 0.94 & Total $=73.47$ \\
\hline Portugal & SovDtD & SovCDS & SovSPR & BankDtD & BankCDS & BankEQU & $\begin{array}{r}\text { Contribution } \\
\text { from others }\end{array}$ \\
\hline SovDtD & 44.95 & 14.36 & 11.51 & 7.33 & 6.49 & 15.37 & 55.05 \\
\hline SovCDS & 11.43 & 22.06 & 27.31 & 17.72 & 15.28 & 6.21 & 77.94 \\
\hline SovSPR & 14.30 & 21.36 & 26.52 & 16.61 & 14.76 & 6.45 & 73.48 \\
\hline BankDtD & 5.39 & 23.37 & 23.13 & 32.27 & 7.45 & 8.39 & 67.73 \\
\hline BankCDS & 20.81 & 16.46 & 20.06 & 9.96 & 25.44 & 7.27 & 74.56 \\
\hline BankEQU & 12.86 & 21.68 & 18.88 & 14.69 & 11.78 & 20.11 & 79.89 \\
\hline Contribution to others & 59.04 & 81.51 & 79.19 & 67.26 & 68.67 & 68.48 & \\
\hline Net contribution & 3.98 & 3.57 & 5.71 & -0.46 & -5.89 & -11.41 & Total $=71.44$ \\
\hline
\end{tabular}


Figure 1: Direct linkages between sovereign and financial institutions

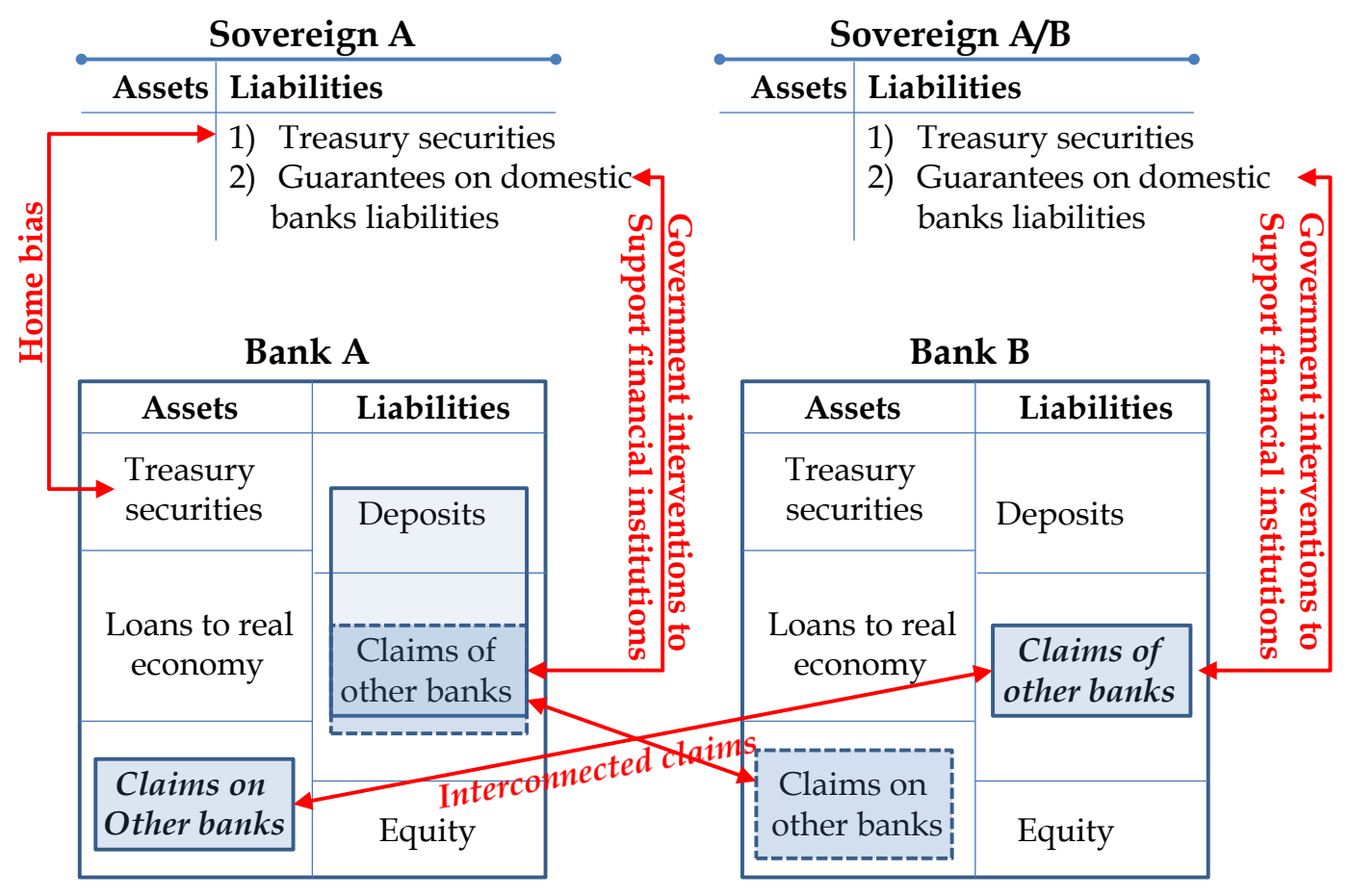


Figure 2: Banking sector average CDS spreads vs Sovereign CDS spreads

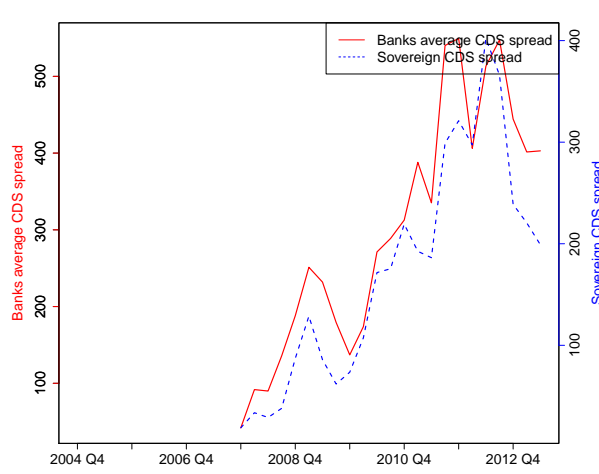

(a) Spain

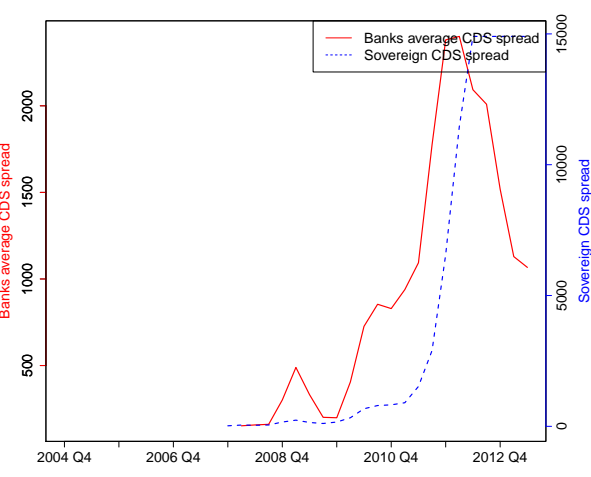

(b) Greece

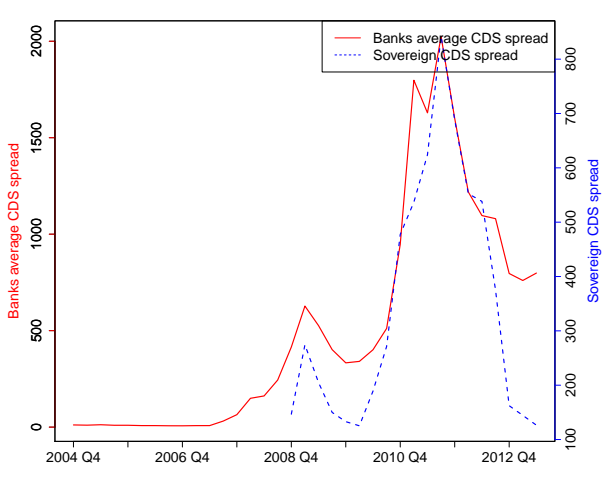

(c) Ireland

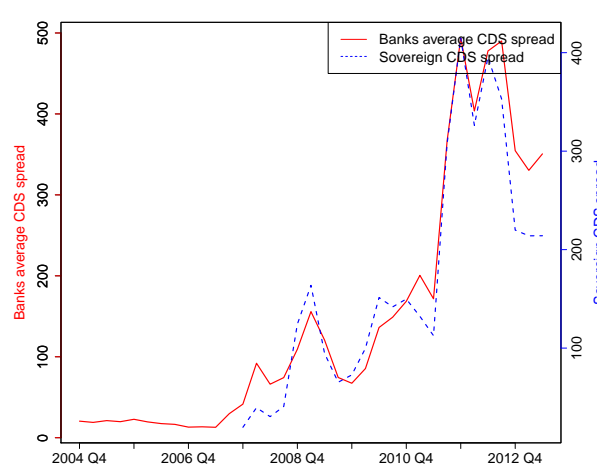

(d) Italy

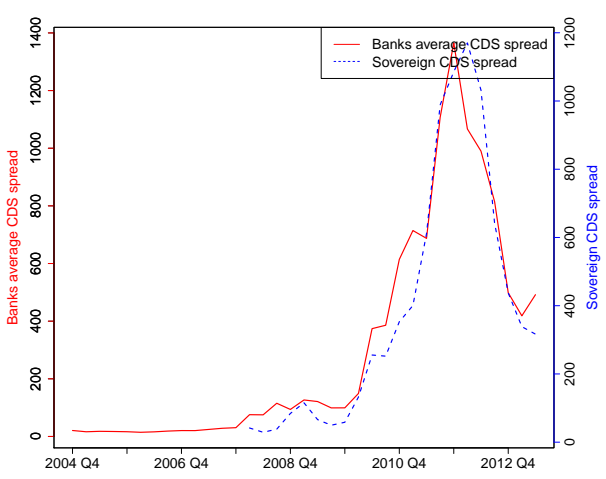

(e) Portugal 
Figure 3: Banking sector average DtD (BankDtD) vs Sovereign DtD (SovDtD)

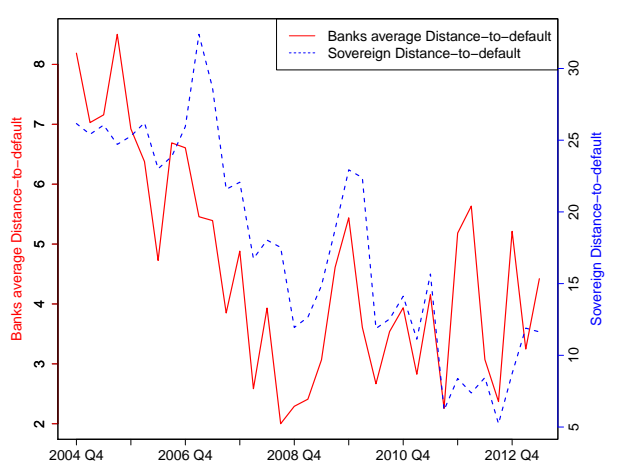

(a) Spain

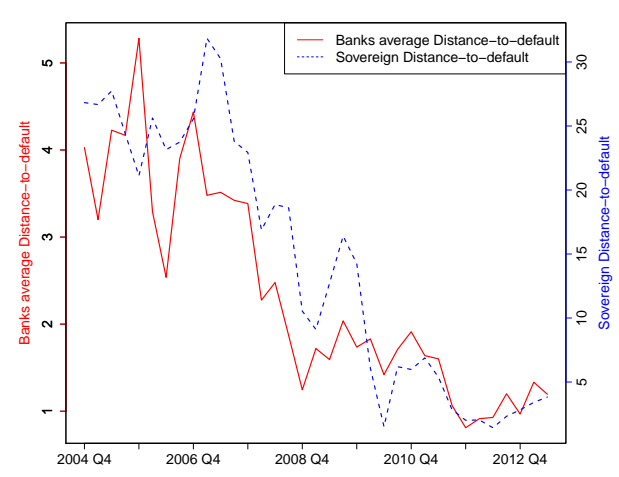

(b) Greece

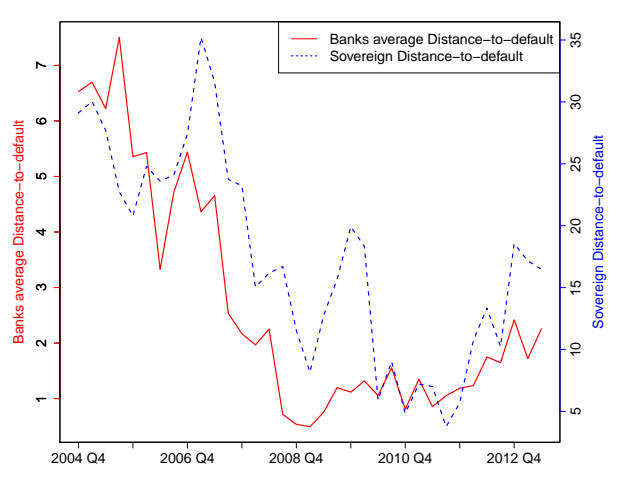

(c) Ireland

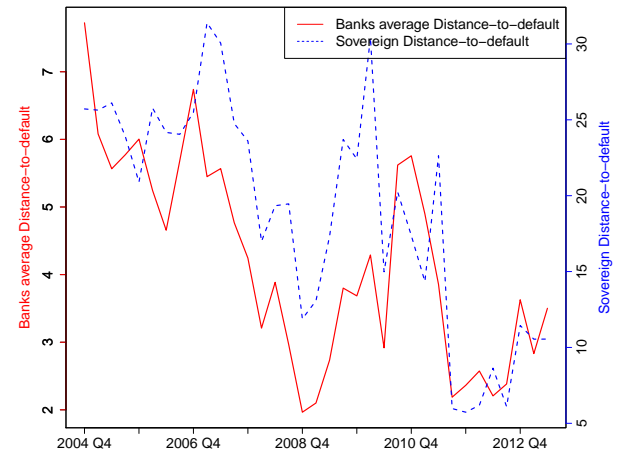

(d) Italy

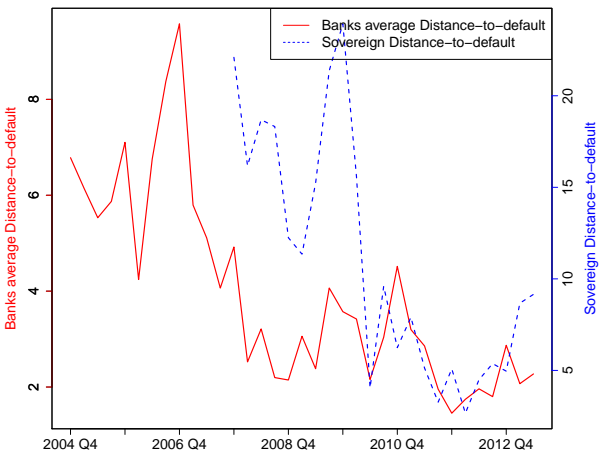

(e) Portugal 
Figure 4: Banking sector equity index (BankEQU) vs Sovereign yield spreads (SovSPR)

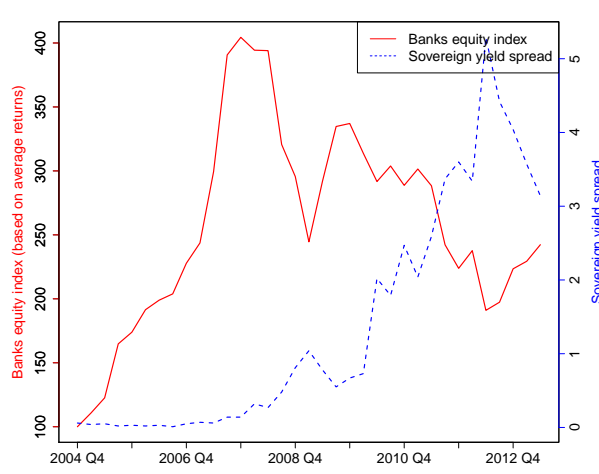

(a) Spain

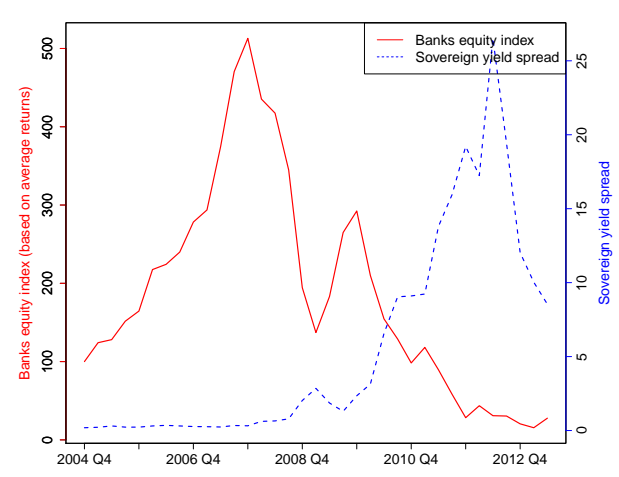

(b) Greece

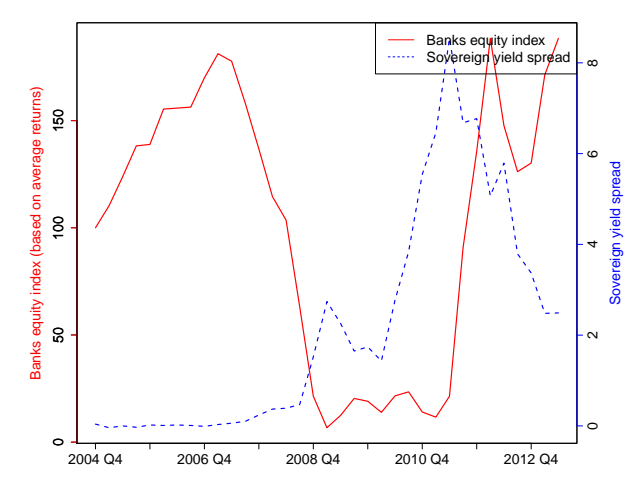

(c) Ireland

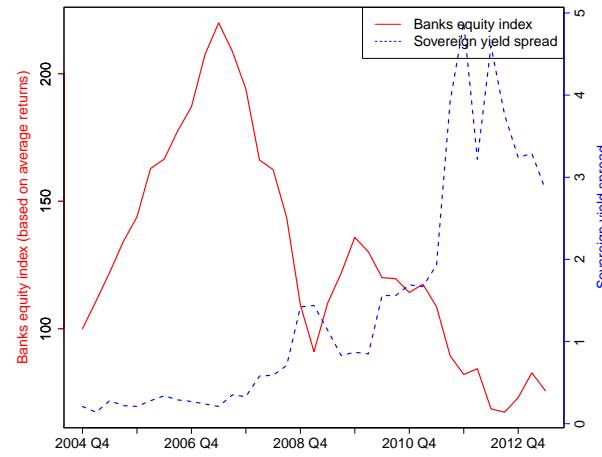

(d) Italy

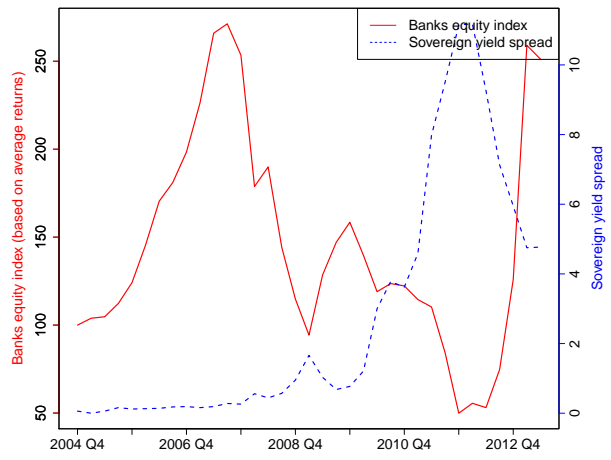

(e) Portugal 
Figure 5: PCA of the normalized indices of sovereign and banking sector credit risk for peripheral euro area countries (2007Q1-2013Q2)

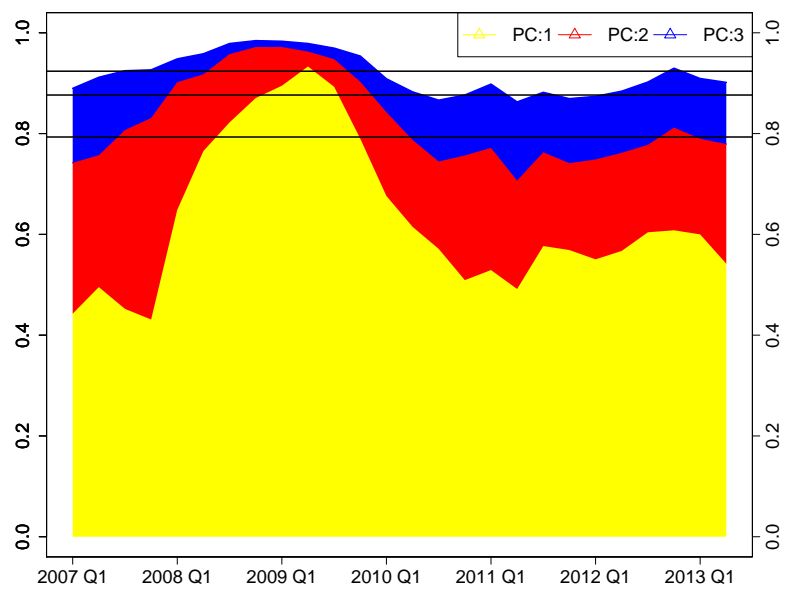

Notes: The figure plots the Cumulative Risk Fraction based on PCA of quarterly sovereign and banking sector credit risk indices based on ten quarter rolling window estimates. The yellow, red and blue areas correspond to the fraction of total variance explained by the first, the second and the third principal component respectively. The horizontal lines represent the same fraction using full-sample estimates.

Figure 6: PCA based on alternative sovereign and banking sector risk indices for peripheral euro area countries

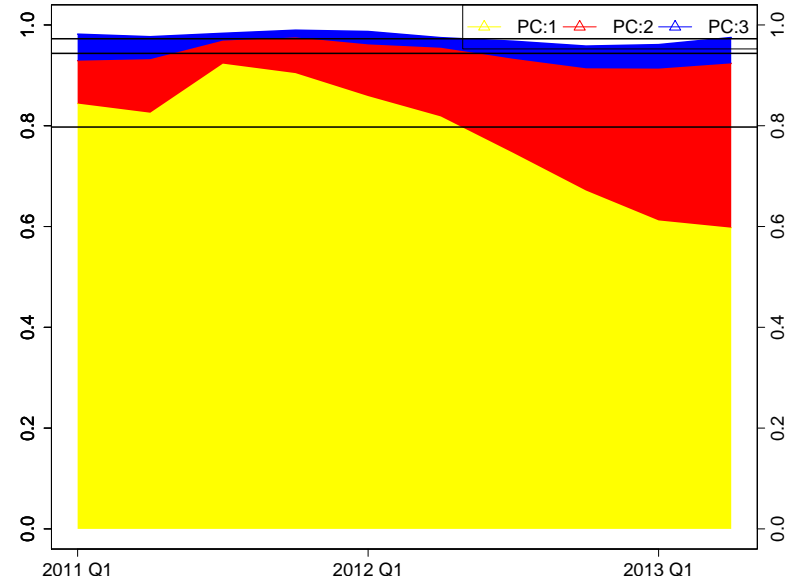

(a) Based on Sovereign and Banking sector CDS (2011Q1-2013Q2)

Notes: Figure (a) plots the Cumulative Risk Fraction based on PCA of quarterly sovereign and average banking sector CDS indices based on ten quarter rolling window estimates. Figure (b) plots the Cumulative Risk Fraction based on PCA of quarterly sovereign yield spreads and banking sector equity index based on ten quarter rolling window estimates. The yellow, red and blue areas correspond to the fraction of total variance explained by the first, the second and the third principal component respectively. The horizontal lines represent the same fraction using full-sample estimates. 
Figure 7: Bi-directional bank-sovereign linkages using dynamic Granger causality (based on sovereign and banking sector DtD indices)

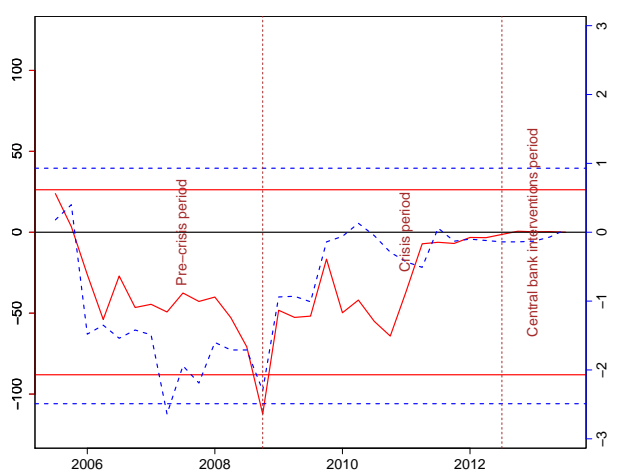

(a) Greece

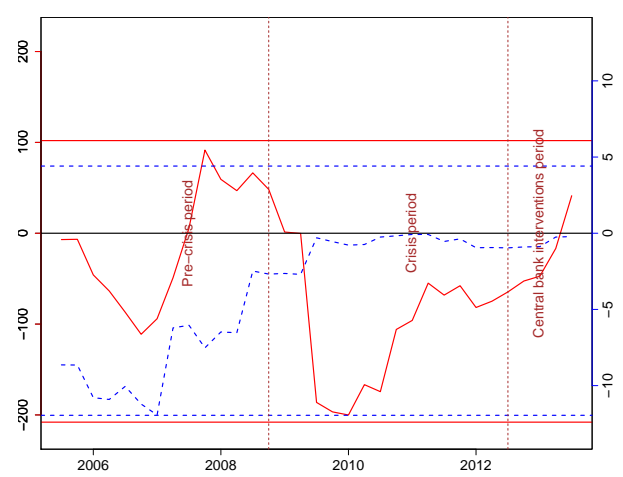

(b) Ireland

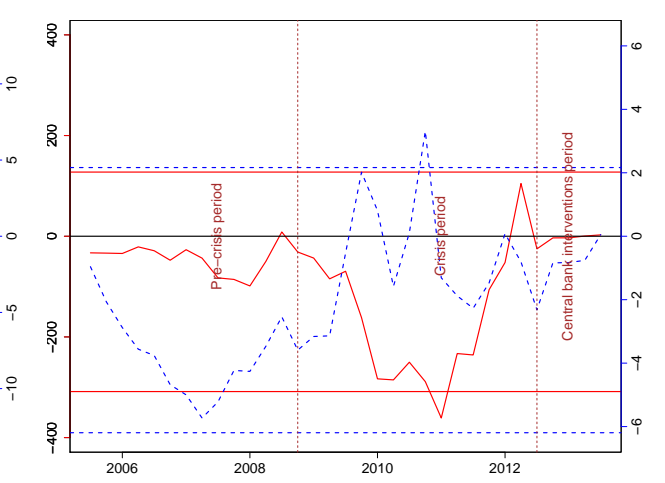

(c) Italy

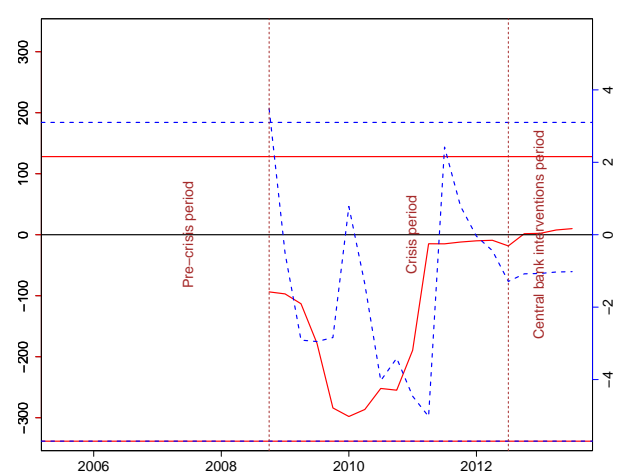

(d) Portugal

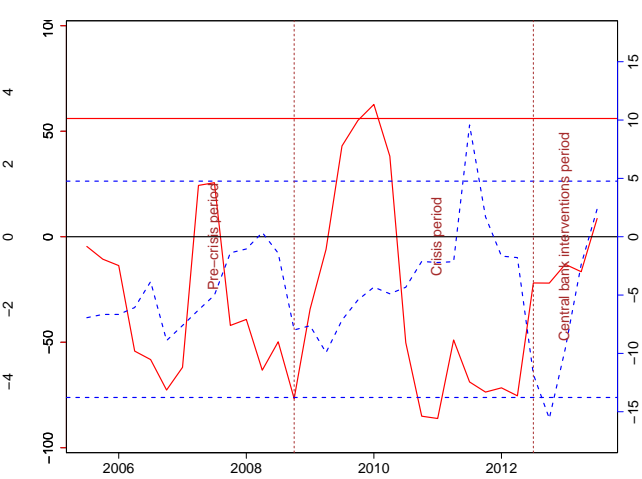

(e) Spain

Notes: The blue dotted line represents dynamic Granger causality from sovereign to banks and that the solid red line represents dynamic Granger causality from banks to sovereign. 
Figure 8: Bi-directional bank-sovereign linkages using dynamic Granger causality (based on sovereign and banking sector CDS indices)

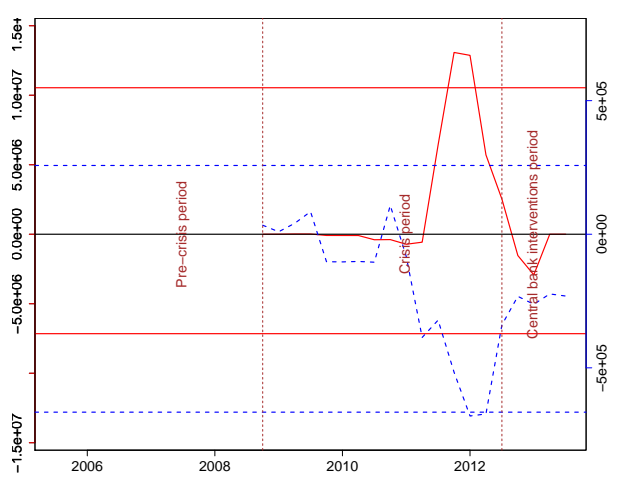

(a) Greece

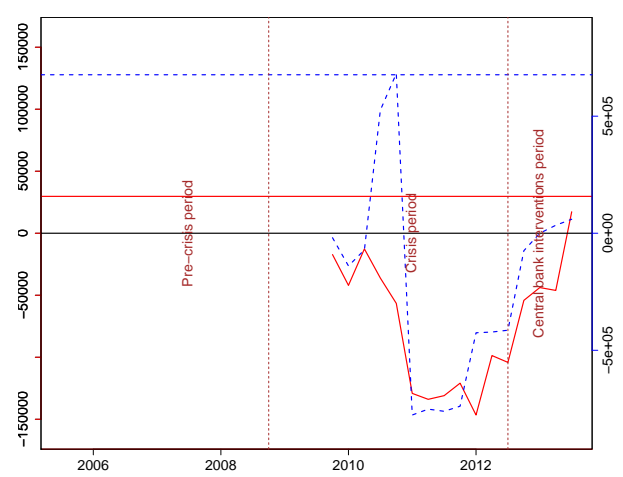

(b) Ireland

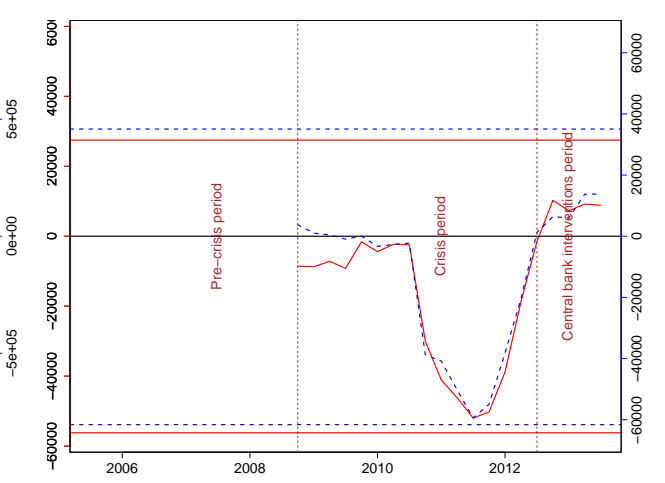

(c) Italy

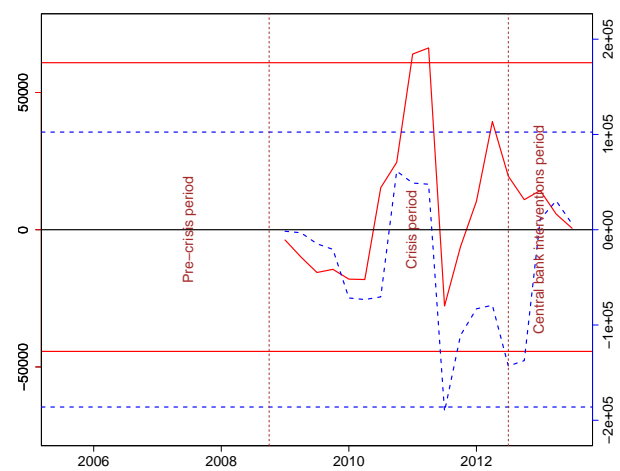

(d) Portugal

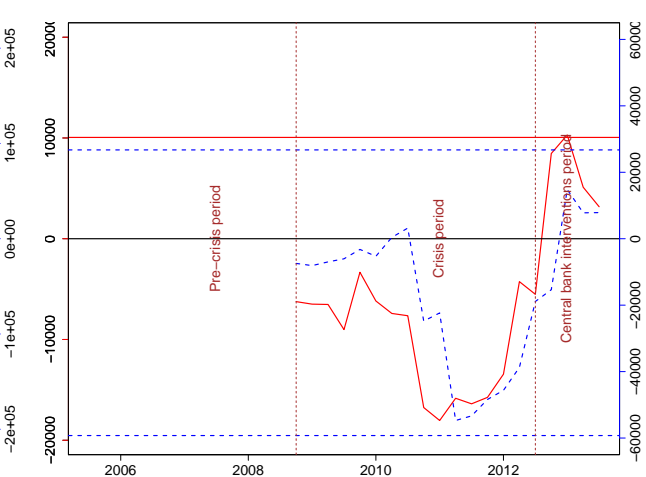

(e) Spain

Notes: The blue dotted line represents dynamic Granger causality from sovereign to banks and that the solid red line represents dynamic Granger causality from banks to sovereign. 
Figure 9: Bi-directional bank-sovereign linkages using dynamic Granger causality (based on sovereign yield spreads and banking sector equity index)

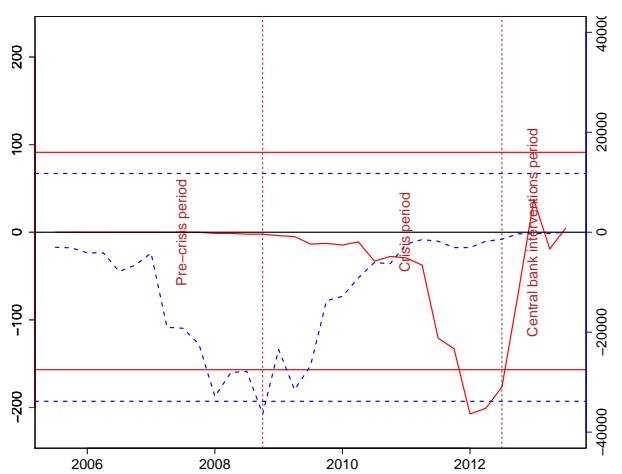

(a) Greece

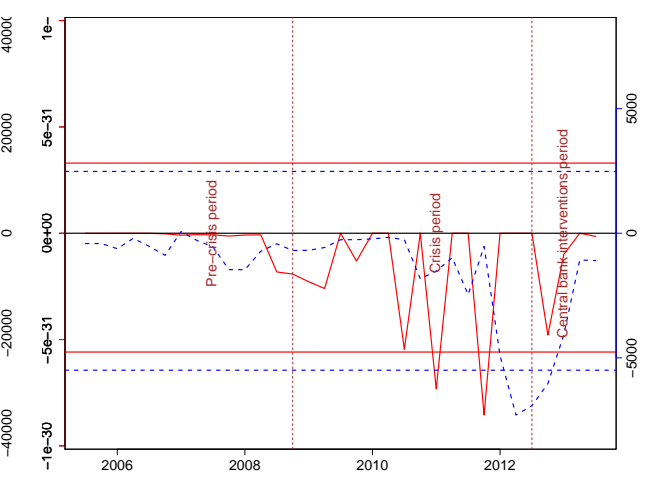

(b) Ireland

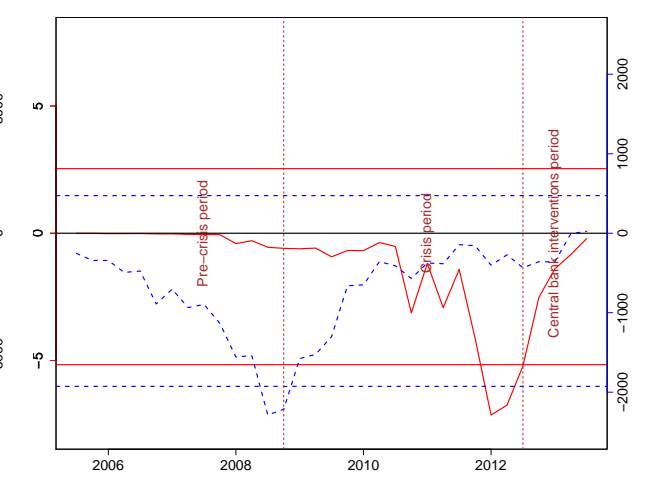

(c) Italy

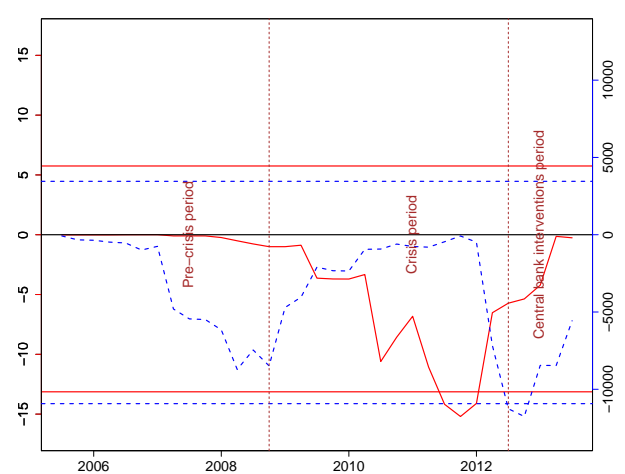

(d) Portugal

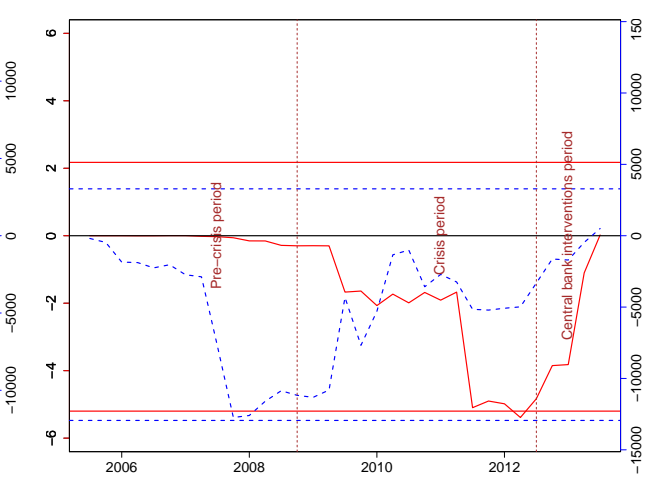

(e) Spain

Notes: The blue dotted line represents dynamic Granger causality from sovereign to banks and that the solid red line represents dynamic Granger causality from banks to sovereign. 
Figure 10: Country-wise net pairwise directional connectedness between sovereign and banking sector risk indicators

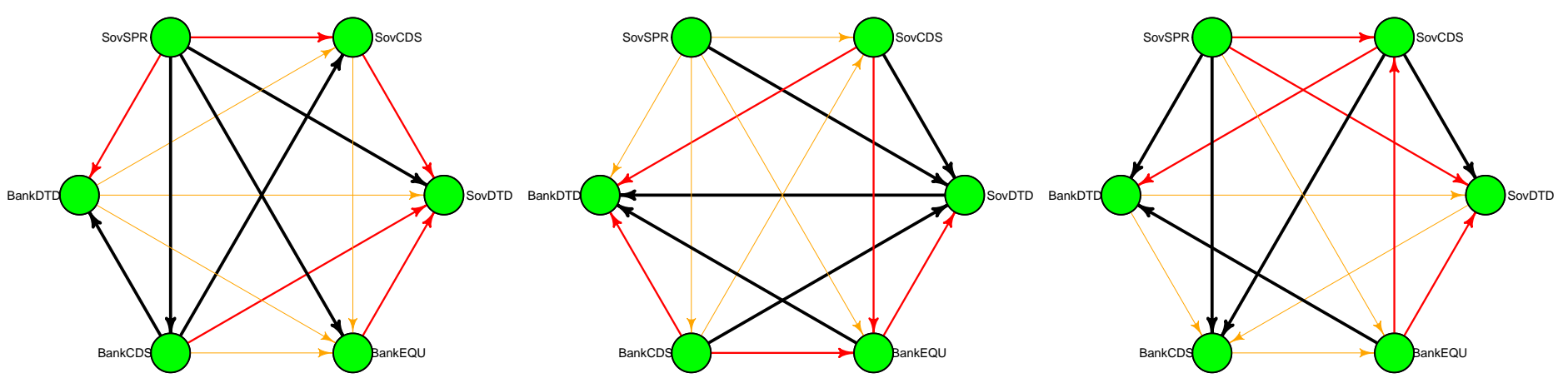

(a) Greece

(b) Italy

(c) Ireland

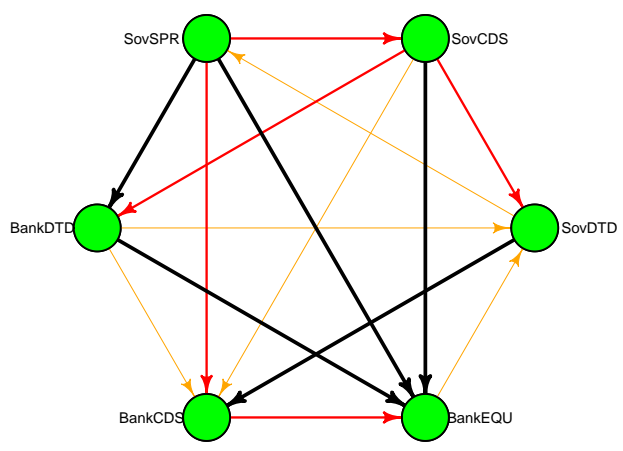

(d) Portugal

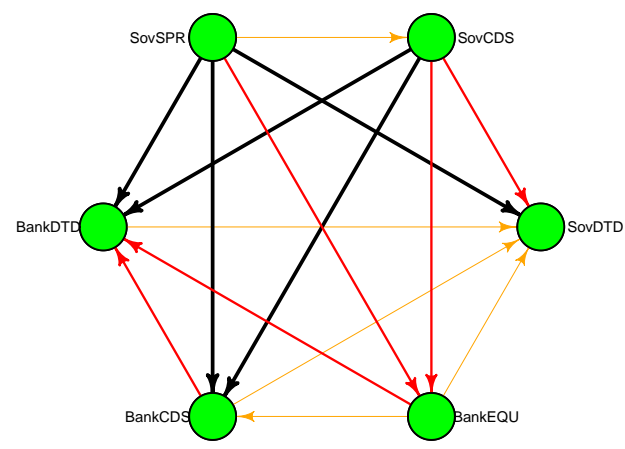

(e) Spain

Notes: To reflect the intensity of the relationship, we use black, red and blue links for very strong, medium and weak intensity respectively. For each country, we first order the computed net directional connectedness values from the highest to the lowest and find the two points that divide the ordered distribution into three parts, each containing a third of the population. SovDTD, SovCDS, and SovSPR stand for sovereign DtD, CDS and yield spread respectively. BankDtD, BankCDS, and BankEQU stand for banking sector average DtD, average CDS and average returns based equity index respectively. 


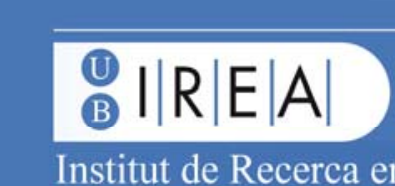

